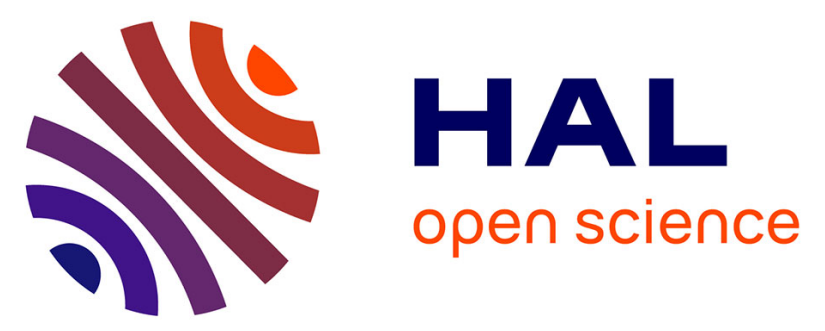

\title{
What is that little voice inside my head? Inner speech phenomenology, its role in cognitive performance, and its relation to self-monitoring
}

Marcela Perrone-Bertolotti, L. Rapin, J. P. Lachaux, Monica Baciu, Hélène Loevenbruck

\section{To cite this version:}

Marcela Perrone-Bertolotti, L. Rapin, J. P. Lachaux, Monica Baciu, Hélène Loevenbruck. What is that little voice inside my head? Inner speech phenomenology, its role in cognitive performance, and its relation to self-monitoring. Behavioural Brain Research, 2014, 261, pp.220-239. 10.1016/j.bbr.2013.12.034 . hal-00967730

\section{HAL Id: hal-00967730 https://hal.science/hal-00967730}

Submitted on 21 Jan 2021

HAL is a multi-disciplinary open access archive for the deposit and dissemination of scientific research documents, whether they are published or not. The documents may come from teaching and research institutions in France or abroad, or from public or private research centers.
L'archive ouverte pluridisciplinaire HAL, est destinée au dépôt et à la diffusion de documents scientifiques de niveau recherche, publiés ou non, émanant des établissements d'enseignement et de recherche français ou étrangers, des laboratoires publics ou privés. 
What is that little voice inside my head? Inner speech phenomenology, its role in cognitive performance, and its relation to self-monitoring

Perrone-Bertolotti, M. ${ }^{1,2,3,4,5}$ CA, Rapin, L. ${ }^{6}$, Lachaux, J-P4 , Baciu M. ${ }^{1,2}$ \& Lœvenbruck, H. ${ }^{1,2,7}$

1 Univ. Grenoble Alpes, LPNC, F-38040, Grenoble

2 CNRS, LPNC UMR 5105, F-38040, Grenoble

3 INSERM U1028-CNRS UMR5292, Brain Dynamics and Cognition Team, Lyon Neuroscience Research Center, F-69500 Lyon-Bron, France;

4 University Claude Bernard, Lyon 1, F-69000, Lyon, France

5 INSERM, U836, Grenoble Institut des Neurosciences, 38700 La Tronche, France

6 Laboratoire de phonétique, Département de Linguistique, Université du Québec à Montréal, Canada

7 GIPSA-lab, Département Parole et Cognition, UMR CNRS 5216, Université de Grenoble, Grenoble, France

CA: Corresponding author Marcela Perrone-Bertolotti Laboratoire de Psychologie \& Neurocognition (CNRS UMR 5105) BSHM, BP47 38040 Grenoble Cedex 9

Tel: $(+33) 0 * 47682-5880$

Fax: $(+33) 0 * 47682-7834$

\section{HIGHLIGHTS}

- Behavioural, physiological and cerebral correlates of covert and overt speech. • Inner speech during reading and writing.

- Inner signing and voice-hallucinations in deaf people.

- Inner speech, mind wandering and cognitive performance.

- Agency during inner speech.

\section{KEYWORDS}

inner speech

inner voice

verbal thoughts

silent reading

inner signing

inner speech monitoring

auditory verbal hallucination

verbal mind wandering 


\section{Abstract}

The little voice inside our head, or inner speech, is a common everyday experience. It plays a central role in human consciousness at the interplay of language and thought. An impressive host of research works has been carried out on inner speech these last fifty years. Here we first describe the phenomenology of inner speech by examining five issues: common behavioural and cerebral correlates with overt speech, different types of inner speech (wilful verbal thought generation and verbal mind wandering), presence of inner speech in reading and in writing, inner signing and voice-hallucinations in deaf people. Secondly, we review the role of inner speech in cognitive performance (i.e., enhancement vs. perturbation). Finally, we consider agency in inner speech and how our inner voice is known to be self-generated and not produced by someone else.

\section{Contents}

1. Introduction

2. Definition of inner speech

3. Phenomenology of inner speech

3.1. Relationship between inner speech and overt speech

3.1.1. Behavioural and physiological correlates of inner speech

\subsubsection{Cerebral correlates of Inner speech}

3.2. Wilful inner speech vs. verbal mind wandering

\subsection{Inner speech and reading}

\subsection{Inner speech and writing}

3.5. Modalities of inner speech: inner signing and voice-hallucinations in deaf people

\subsection{Summary so far}

4. The influence of inner speech on cognitive performance

4.1. Inner speech and task-switching

4.2. Inner speech and problem-solving

4.3. Inner speech and rumination

5. Agency during inner speech

5.1. Agency within predictive modelling of inner speech

5.2. Evidence for "inner speech is an action"

5.3. A case of impaired inner speech

6. Conclusion 


\section{Introduction}

We all hear a voice inside our brain, commonly called "inner voice", "inner speech" or referred to as "verbal thoughts". Inner speech is directed by oneself to oneself, and is produced in one's mind. Inner (silent) rehearsal plays a central role in the temporary storage of information in short-term memory (phonological loop). Silently verbalizing is also crucial in thinking and self-awareness. It helps in planning, problem-solving, self-motivating, reading, writing, calculating and autobiographical memory. Inner speech can thus have a positive influence on many cognitive tasks. But it can be disrupted and have a negative role. Excessive negative self-reflecting or mental rumination can interfere with cognitive performance and has been shown to be a risk factor for depression and anxiety disorders. It is also suggested that inner speech monitoring deficit may result in auditory verbal hallucinations (AVH), where one's own verbal thoughts come to be perceived as external voices. Before we examine several questions related to the phenomenology of inner speech, its role in cognitive performance and its relation to self-monitoring, we will first define inner speech, based on several descriptions from the literature.

\section{Definition of inner speech}

Inner speech, silent-, imagined-, covert- speech, verbal thought, are some of the terms used to refer to the silent production of words in one's mind, or the activity of talking to oneself in silence [1]. It has also been defined as the silent expression of conscious thought to oneself in a coherent linguistic form [2]. Inner speech plays a central role in human consciousness at the interplay of language and thought $[3,4]$. It is a pervasive and significant human mental activity. It is estimated that at least one quarter of people's conscious waking life consists of inner speech $[5,6]$. Inner speech can be considered as the mental simulation of speech. As such it can contribute to the understanding of speech representations or of speech planning and preparation. Inner speech is central in various cognitive functions. It has been suggested that inner speech may interact with working memory in order to enhance the encoding of new material $[7,8]$. Inner speech is also involved in rehearsing past communication, situation and emotions or in past situation recall (autobiographical memories) [4]. Inner speech also plays a crucial role in future situation planning, in thinking [9] and in consciousness, self-awareness and self-regulation (see $[4,10,11])$. It is also implicated in reading and writing [12-14]. From a developmental point of view, Vygotsky [2] believed that inner speech derived from external speech according to a gradual developmental process of internalisation, with younger children only able to "think out loud" (see also [15-17]). According to Vygotsky and Conrad, it is not until about age 
5 years or even later that children's overt verbal production can become fully internalized. This strong claim is contradicted by recent evidence, however, suggesting that infants may use inner speech. Mani and Plunkett [18] have shown that 18-month old infants can implicitly name objects. These internally generated names can prime infants' subsequent responses in an object - spoken word matching task. Ngon and Peperkamp [19] have shown that 20-month olds infants can covertly produce word-forms that they do not yet produce overtly, and can categorize them as mono- vs trisyllabic items. Therefore an alternative view is that children can produce a form of inner speech, a capacity that could in fact facilitate their oral language development. From a pathological point of view, it is suggested that dysfunction of inner speech represent symptoms of several mental health disorders (mental rumination in depression or auditory verbal hallucinations in schizophrenia), which reinforces its role in self-awareness and self-regulation. Agnati et al. [20] have gone a step further. They argue that inner speech is usually a positive aid to learning and reasoning. They propose that inner speech conferred an important ability for the planning of behaviour by individuals, within the complex environment typical of early human societies. They thus view inner speech as an exaptation, in Gould and Vrba's [21] sense. They add that, in certain circumstances, inner speech can be regarded as a mis-exaptation. When inner speech becomes too intense, it can become a pathological symptom, such as the insistent imperative inner voices that characterise schizophrenia or the excessive rumination that accompanies social anxiety and depression. Overall, inner speech is pervasive and very common and it is hard to prevent oneself from generating verbal thoughts. Yet we do not have a thorough understanding of it and many questions can be raised.

\section{Phenomenology of inner speech}

The nature of inner speech, its characteristics and manifestations have been the focus on many research studies. First, the relationship between inner and overt speech is still debated. Are the behavioural, physiological and cerebral correlates of inner speech similar to those of overt speech? Precisely, does inner speech involve articulatory representations and are the cerebral networks involved in overt speech also recruited in inner speech? Can inner speech be conceived of as an action or is it a processing of remembered speech percepts? Secondly, inner speech can have several manifestations. It can be wilful when we mentally recite a poem, but it can also be more unconstrained, when our "mind wanders" during resting states. Is verbal mind wandering a different phenomenon from the more voluntary inner speech? Are there different cerebral networks associated with the 
different types of inner speech? Thirdly, one interesting situation is silent reading. Do we always engage in inner speech when we read silently? Moreover do we systematically use inner speech when we write? Finally we will examine what inner verbal production consists of in deaf signers and how voicehallucinations in deaf people can be interpreted.

\subsection{Relationship between inner speech and overt speech}

The relation of inner to overt speech is still unclear, and it is a highly debated issue to which degree they are related. Inner speech is generally thought of as a truncated overt speech. But where the truncation exactly lies is the matter of many debates.

\subsubsection{Behavioural and physiological correlates of inner speech}

Early descriptions of the relationship between inner and overt speech can be traced back to the behaviourist view of verbal thought. Watson [22] viewed thought as associated with covert speech production: "thought processes are really motor habits in the larynx" (p. 174). He further described covert speech (referred to as "implicit language") as a weakened form of overt speech, involving faint actions that are " abbreviated, short-circuited and economized » (Watson [23], p. 327). In other words, it was suggested by Watson that movements of the speech articulators occur during covert speech. This strong view of the resemblance of inner speech with overt speech and of the presence of movement during thinking has been refuted, however. Smith et al. [24] administered curare to a participant to induce head, lip, jaw, and eyelid paralysis. While the participant was totally incapable of articulation he still remained able to comprehend and answer questions accurately through left eyebrow contraction. This experiment suggested that thought, and inner speech, can occur without articulation. Later subjective accounts described inner speech as frequently resembling overt speech, in that it is sound-based and it can vary in tempo, pitch and rhythm (see e.g. [25]). This close resemblance has led some researchers to argue that inner speech production is the same thing as overt speech production, except that motor execution is blocked and no sound is produced. This "motor simulation" view implies that inner speech and overt speech represent a continuum, share common mechanisms and have similar physiological correlates (see [26], on covert actions in general). Among potentially similar physiological correlates are respiration rate and speaking rate. As concerns respiration rate, Conrad and Schönle [27] examined breathing in overt speech, subvocal speech (articulatory movements without sound production), and inner speech (without articulation or vocalization) and rest. They found that resting respiration changed to speech respiration along a 
continuum from inner, through subvocal, to overt speech. This transition manifested itself in a progressive increase in the duration of the expiratory phase. Conrad and Schönle concluded that this progressive change towards speech respiratory patterns indicated a progressive activation of the speech motor system. With regards to speaking rate, Netsell et al. [28] have examined covert and overt sentence production in persons who stutter (PWS) as well as typical speakers. Participants themselves timed their sentences with a start/stop key on a keyboard. The duration of a sentence was divided by the number of syllables in the sentence. Netsell et al. found that speaking rates of overt and covert speech were not significantly different for typical speakers. But PWS were significantly slower in overt speech compared to inner speech. In addition, the PWS filled out a questionnaire regarding the history and nature of their stuttering. Six of the seven PWS reported they were $100 \%$ fluent with inner speech. The self-reported most severe stutterer said he was $100 \%$ fluent with inner speech. Altogether, these findings suggest that inner speech and covert speech have similar physiological correlates in typical speakers. The fact that stutterers are fluent when using inner speech suggests that inner speech may use more abstract representations than overt speech. This calls for a revision of the motor simulation view.

An alternative hypothesis to the motor simulation view states that mental simulation of speech is limited to rehearsing early stages of speech production, well ahead of articulation (see e.g. [16]). This latter hypothesis is referred to as the "abstraction view", for which the experience of inner speech is unconcerned with actual motor simulations. It is opposed to the "motor simulation view" for which inner speech does include articulatory detail.

To further assess the relationship of inner speech to overt speech behaviourally, authors often evaluate speech errors (such as phonological or phonemic errors). If speech errors are present during covert speech production, like they are during overt speech, it can be inferred that inner speech and overt speech are similar. For instance, Oppenheim and Dell [29] looked for inner speech slips via a tongue-twister recitation task. They specifically focused on lexical bias (i.e., phonological errors demonstrating a tendency to create words more often than nonwords during tongue-twister repetition) and on phonemic similarity effects (i.e., the tendency for phoneme substitution errors to occur between phonemes that share similar? features). This allowed them to evaluate, on the one hand, activation spreading between lexical and phonological representations, and on the other hand, activation of sub-phonemic feature representations. Their results suggest that a lexical bias was observed in both inner and overt speech, but that the phonemic similarity effect was only observed in overt speech, suggesting a lack of phonemic representation (i.e., articulatory or phonetic features 
representation) during inner speech. These findings first suggest that inner speech has much in common with overt speech, since it displays slips that exhibit one of the most important error effects during overt speech, lexical bias. But they also suggest that inner speech is impoverished compared to overt speech and that inner speech is abstract and underspecified the featural level. According to Oppenheim and Dell [29] there would be no feedback of activation from feature to phoneme levels of representation, and thus no bottom-up activation of competitor phonemes. More specifically, the authors propose that either poor generation of features during inner speech production or poor sensitivity to features during its perception could suppress the effect of phonemic similarity. To further test the hypothesis that inner speech is abstract, Oppenheim and Dell [30] contrasted two forms of inner speech, standard inner speech without articulatory movement and an intermediate form with silent articulation. They showed that the intermediate inner speech elicited phonemic similarity effects, just as overt speech, while the standard inner speech did not. They interpretation is that silent articulation increases the amount of activation of articulatory (subphonemic) features, thereby increasing the number of errors involving similarly articulated phonemes. In contrast, they observed a lack of phonemic similarity effect in standard unarticulated inner speech. According to them, these findings support a modified version of the abstraction view, the "flexible abstraction hypothesis": Inner speech has multiple facets, it may fail to involve articulatory representations but it can incorporate lower level articulatory planning when speakers silently articulate.

A somewhat different view is taken by Brocklehurst and Corley [31]. In a similar experimental protocol as that used in Oppenheim and Dell [29], they observed a phonemic similarity effect during inner speech. Brocklehurst and Corley [31] propose that the lack of phonemic similarity effect reported in Oppenheim and Dell's study [29] may be related to the fact that such errors may be difficult to perceive internally. By adding an auditorily masked condition and by using a mix of real-and non-words, they found phonemic similarity effects of similar magnitudes in both inner and overt speech. This suggests that inner speech is not impoverished at the featural level as previously claimed. Furthermore, in a later study [32], using the real words material from Oppenheim and Dell [30], they found no interaction of phonemic similarity with overtness in predicting the likelihood of a substitution error. The effects of phonemic similarity were manifest in both inner and overt speech, both with and without auditory feedback. Their interpretation is that inner speech must be specified at the sub-phonemic level and that inner speech is produced in much the same way as overt speech.

The fact that different results were obtained by different research groups could suggest that inner speech in fact consists of different subtypes or levels and that in each of the subtypes, flexibility 
is at play, as argued by Oppenheim and Dell themselves. In that vein, Geva and colleagues distinguish two levels of inner speech, an abstract and a concrete one [33]. They define abstract inner speech as the 'language of the mind', which involves the activation of abstract linguistic representation. According to them, abstract inner speech has been the object of many research works in experimental psychology, from Egger [34] and Ballet [35] and including Vygotsky [2], to Dell and Repka [36], for instance. The second level of inner speech, or concrete inner speech, is characterized by Geva et al. [33] as flexible, being either phonological or phonetic. The research works by Oppenheim and Dell [30] or Brocklehurst and Corley [31] presented above are related to this level. The major difference between these two levels is the potential involvement of low-level phonetic information (such as articulatory features) during concrete inner speech only. Different levels of inner speech are also posited by Fernyhough [37]. Elaborating on Vygotsky's idea that inner speech is the end result of a gradual process of internalisation of dialogue, Fernyhough has sketched out a model of inner speech development that includes four levels. At level 1 (external dialogue), children and caregivers engage in overt dialogue. At level 2 (private speech), children conduct these dialogues in their own overt private speech, which becomes gradually subvocalised. At level 3 (expanded inner speech), private speech is fully internalised and covert but its dialogic quality is still manifest. At level 4 (condensed inner speech), syntactic and semantic transformations convert inner speech into an abbreviated dialogue. This last level corresponds to the stage of "thinking in pure meanings", described by Vygotsky, in which inner speech has lost most of the acoustic and structural qualities of external speech. Interestingly, Fernyhough suggests that, even in adulthood, movements between the levels may occur. Under demanding conditions, such as cognitive load or stress, there could be a transition from fully condensed inner speech back to expanded inner speech and even back to private inner speech. Although the plausibility of the gradual developmental process is debatable (see section 2), the proposition that inner speech evolves along varying levels has intuitive appeal. Who hasn't « thought out loud » in conditions of danger or stress?

\subsubsection{Cerebral correlates of Inner speech}

Further information about the relationship between overt and covert speech comes from the comparison between neural correlates of inner and overt speech (see [38] or [39] for detailed reviews). In agreement with the view that inner speech and overt speech may belong to the same continuum, many studies have shown common networks of activation in tasks that involve either covert or overt speech. In general, both overt and covert speech tasks induce activation of essential language areas (Broca's and Wernicke's areas, inferior parietal lobule) in the left specialized hemisphere (e.g. [40-46]). However, several neuroimaging studies that directly include within-subject comparison of inner and 
overt speech tasks [33, 40-42, 44, 47-55], suggest that although inner and overt speech share a common cerebral network, they engage some cerebral regions in different ways and they produce separate activations in other cerebral regions (see Table 1).

Some studies have found greater activation in overt speech relative to inner speech in motor and premotor cerebral regions (e.g. [44]). These findings are consistent with the continuum perspective, in which inner speech is considered as covert speech with a blocking of execution processes. Other studies suggest that covert speech is not just inner speech with added motor processes, however. Greater activation has been observed in overt relative to inner speech tasks in regions such as the left inferior frontal gyrus, the left insula, sensory areas, the left superior temporal sulcus, the supramarginal gyrus, the anterior cingulate or the left and right paravermal lobule VI (e.g. $[40,42,44,48,50,51])$. Greater activation in auditory areas has been postulated to be associated with the perception of one's own speech and greater response of the left insula has been related to its role in articulatory planning.

Conversely, greater activation was observed in inner speech relative to overt speech in several regions including the left precentral gyrus, left middle frontal gurys, left or right middle temporal gyrus, left superior frontal gyrus, right cingulate gyrus, left or right inferior parietal lobe, left dorsal frontal cortex, left parahippocampal gyrus, right cerebellum (e.g. [41, 48, 51]). These observations imply that covert speech generation cannot be simply equated to overt responses minus articulatory motor execution. Several interpretations have been proposed. First, some of the authors cited above have suggested that increased activity in inner compared to overt speech could reflect greater overall signal variance in overt conditions due to greater head motion. Secondly, some of these activations (e.g. in inferior and superior parietal, superior frontal, anterior cingulate, and middle temporal regions) have been attributed to inhibition of overt responses or movement-related conflict (producing a word but not saying it aloud).

The varying results can be explained by the different types of inner speech tasks involved in the studies listed here. The different tasks (which include word repetition, letter or object naming, animal name generation, verb generation, reading, rhyme judgement, counting) involve different speech 
production processes, from lexical retrieval to phonological or even phonetic encoding. These processes engage different brain regions and are associated with different degrees of monitoring, i.e., with varying degrees of awareness (see e.g [56]). Rhyme and homophone judgement tasks, for instance, involve active use of inner speech. In these tasks, participants have to monitor their own inner speech, keep the first presented item in working memory, while they process the second item. Phonological awareness is crucial in these tasks, as well as a high level of attention to one's inner speech. In semantic fluency tasks (such as word generation), monitoring is also crucially involved, to keep track of the words already produced. In contrast tasks such as word repetition, recitation, letter naming, silent reading or counting, require less monitoring. Evidence for the fact that different degrees of awareness to one's own inner speech lead to different patterns of brain activations was provided by an fMRI study of the verbal transformation effect [57]. 'Verbal transformation' refers to the perceptual phenomenon in which listeners or speakers report hearing a new percept when a word is repeated rapidly [58]. In the study by Sato and colleagues, participants were asked to silently repeat pseudowords such as /psə/. In the baseline condition, participants were asked to covertly repeat the sequence over and over (/psə psə psə psə psə .../). In the verbal transformation condition, they had to covertly repeat the sequence and actively search for a transformation (from /psə/ to /səp/ for instance). When compared with the baseline condition, inner speech with active search for verbal transformation correlated with stronger activation in the left inferior frontal gyrus and left supramarginal gyrus, as well as other regions (anterior part of the right cingulate gyrus, bilateral cerebellum and left superior temporal gyrus). These results suggest that when inner speech involves actively conscious phonological processes, the left inferior frontal gyrus and left supramarginal gyrus are more strongly activated. They further support the assumption that different degrees of awareness during the monitoring of one's own inner speech are associated with different patterns of brain region activations.

A further source of difference between these results is that most of these studies fail to control for participants' performance during the inner speech condition. To overcome these methodological pitfalls, Geva et al. [33] carried out a lesion analysis study. In their study, patients with chronic poststroke aphasia performed covert phonological tasks (rhyme and homophone judgement) in which behavioural performance was monitored, as well as a reading aloud task to assess overt speech. The authors performed a voxel-based lesion-symptom mapping, allowing the examination of anatomical correlates of inner speech and their relation to overt speech, although not directly comparing covert and overt tasks. Their findings suggest that difficulties with tasks requiring inner speech are associated with lesions to structures in the left inferior frontal gyrus (pars opercularis) and in the left 
supramarginal gyrus and white matter regions adjacent to it, even when reading aloud (overt speech) was factored out. They suggest that inner speech cannot be simply described as overt speech without a motor component. In line with this suggestion, there is also evidence that inner and overt speech can dissociate in aphasia $[13,59]$, see also $[60,61]$.

Most of the neuroimaging studies listed above are limited on their temporal or spatial resolution, however. Electrocorticography (ECOG) from the surface of the brain provides a promising tool for the study of the relationship between inner and overt speech. Pei et al. [62] recorded ECoG during a 'word repetition' task in nine patients with intractable epilepsy. The task was in fact broken into a word reading task (visual stimuli presentation) and a word repetition task (auditory stimuli presentation). Changes in ECoG amplitudes in the high gamma band (HGB) were observed during overt and covert word repetition. Overt word production was primarily associated with changes in the superior and middle parts of temporal lobe, Wernicke's area, the supramarginal gyrus, Broca's area, premotor cortex and primary motor cortex. Covert word production was primarily associated with HGB changes in superior temporal lobe and the supramarginal gyrus. Although this study is impressive, it has several limitations. First the electrode coverage was incomplete (almost all subjects had grids placed on the left hemisphere but not on the right and the density of the electrode distribution over the frontal lobe was higher than over the temporal lobe) and varied across participants. Second, the verbal response was only recorded in 5 of the 9 participants. And lastly, the 'word repetition' tasks did not examine all aspects of word processing, let alone inner speech.

To sum up, the relationship between inner speech and overt speech is still a matter of debates. Many similarities between inner and overt speech have been shown. Inner speech can be seen as a truncation of overt speech, but the level at which the speech production process is interrupted (abstract linguistic representation vs. articulatory representation) is still debated. Overt speech is not just inner speech with added motor processes. Greater activation in auditory areas, for instance, is associated with the perception of one's own overt speech. Furthermore, inner speech seems to recruit some cerebral regions that are not recruited in overt speech. Some of these activations can be attributed to inhibition of overt responses or response conflict.

\subsection{Wilful inner speech vs. verbal mind wandering}

Another feature concerns the way inner speech manifests itself. We sometimes deliberately engage in inner speech (e.g. counting objects), which can be called "mental speech generation" or "deliberate covert production of speech", but sometimes our internal monologue is less deliberate. 
This less deliberate inner speech can be referred to as "verbal mind wandering", and often occurs during "resting states" (it is important to highlight that mind wandering can also occur in non-linguistic forms, such as mental imagery). It consists of flowing, spontaneous, unconstrained, stimulusindependent verbal thoughts. Voluntary mental verbal generation is an attention-demanding task that has been associated with the task-positive network (e.g. [63]). The task-positive [64] or multiple demands network [65] involves regions that are routinely activated during goal-directed task performance. It includes the dorsolateral and ventral prefrontal cortex (PFC), premotor cortex, lateral parietal regions, occipital regions, anterior cingulate cortex (ACC), and insula.

Verbal mind wandering, which often occurs during resting states is a pervasive human state. It involves stimulus-independent thought (e.g. [66-68]). It is often associated with the default mode network (DMN) (e.g [69] for a review). The DMN consists of dorsal and ventral medial PFC, posterior cingulate cortex and precuneus, posterior inferior parietal regions, lateral temporal cortex, and the hippocampal formation including parahippocampus [70-73].

Verbal mind wandering and voluntary mental verbal generation have opposite relationships with the DMN. Verbal mind wandering occurs at rest, but can also occur intermittently during periods of sustained attention $[68,74]$. Functional connectivity studies have shown that the DMN and attention networks fluctuate in an anticorrelated and regular pattern [73]. To simplify, one type of inner speech, voluntary verbal thought, involves the task-positive network, whereas the other (verbal mind wandering) involves the DMN. Further research is needed to account for these two modes of inner speech that seem to activate separate networks. Indeed, in patients with schizophrenia, these anticorrelated patterns between DMN and task-positive network could be disrupted. In a comparison of patients with schizophrenia and healthy participants, in both speech perception and verbal thought generation, Rapin et al. [63] found higher activity in the superior temporal gyrus as well as in the DMN, in patients than in controls. In addition, deactivations were found in prefrontal regions normally associated with the task-positive network (i.e., in the allocation of attentional resources). This pattern of hyperactivations and deactivations in schizophrenia patients may be particularly important for understanding inner/outer confusion. Hyper-intense cooperation between functional networks involved in self-reflection and those involved in perception of language suggests rich auditory qualities associated with lower prefrontal cortex activation, may contribute to inner/outer confusion in these patients. 
It could also be interesting to examine whether these two modes correspond to different degrees of abstraction. As explained above (section 3.1), there seem to be different instantiations of inner speech. Abstract instantiations correspond to abstract linguistic representations. Concrete instantiations would be more flexible, involving either phonological or phonetic representations. We speculate that verbal mind wandering may correspond to an abstract instantiation of inner speech whereas voluntary verbal thought may correspond to a more concrete instantiation, during which errors could be evaluated, for instance. Further behavioural and neuroimaging studies are necessary to better characterize these different modes of inner speech.

\subsection{Inner speech and reading}

Silent reading engages different levels of processing (e.g., orthographic, semantic, phonological, syntactic, emotional...) but also implies the experience of listening to a voice (see [12]). There is currently little empirical work related to inner speech and the percepts evoked by silent reading. It has been recently suggested that silent reading often involves an imagery speech component or Auditory Verbal Imagery (AVI, [75]). Evidence for inner speech during reading has recently been provided by experimental psychology. Several studies suggest that silent reading is modulated by the knowledge of the presumed author's speaking speed [76], the talker's voice familiarity [77] or the reader's regional accent [78]. For instance, Alexander and Nygaard [76] manipulated the speaking rate of the author of a text to be read (slow vs fast). Participants were briefly familiarized with two talkers, one with a slow and another with fast speaking rate. Thereafter, participants were instructed to perform a reading task, aloud or silently. They were told that the text was written by either the fast or the slow talker. They found that participants took longer to read passages 'written' by the slow talker than passages 'written' by the faster talker, both when reading aloud and silently. This indicates that participants accessed the author's speaking rate when reading. When the text was difficult, the difference in reading times increased, suggesting that talker-specific auditory imagery was more likely to occur when reading difficult text. Alexander and Nygaard's interpretation is that readers may engage in a type of auditory imagery for the perceptual characteristics of a talker's voice when reading text. One possible explanation they pointed out about the effect of text difficulty during reading is the fact that phonological representations may be unnecessary when silently reading easy texts because a direct route from orthographic to meaning may be used (see also [79] for similar effects at the cerebral level). Another possible interpretation is related to attentional control involved during difficult text reading; readers may have simply attended to the difficult passages to a greater extent and may have engaged in a more elaborative processing (see below [14]). The occurrence of inner speech during silent reading 
has also been recently confirmed by neuroimaging experiments [14, 80-82]. These studies made the assumption that if silent reading generates AVI, similar cerebral activations should be observed during silent reading and speech perception (bottom-up). It is known that several areas in the auditory cortex, called voice-selective areas or temporal voice areas, are selectively involved during human voice perception (TVA, see [83]). TVA is located along posterior and middle parts of the right superior temporal sulcus. The assumption is that TVA should be involved in silent reading, just like it is during voice perception.

This assumption was validated by Yao et al. [80] using fMRI. In their study, direct (e.g., Mary said: "I'm hungry") and indirect (e.g., Mary said that she was hungry) speech sentences were visually presented during a silent reading task. Direct speech is generally assumed to be more vivid and to induce more perceptual simulation (or imagery) than indirect speech. Their results showed that the direct speech condition induced a greater BOLD signal in the TVA of the right auditory cortex than the indirect speech condition. Further, in this study, participants were not encouraged to imagine specific voices during reading, and for this reason authors suggest that voice-related perceptual representations were automatically activated when silently reading direct speech statement. The authors suggest that their results are consistent with the embodied cognition hypothesis [84, 85], suggesting perceptual simulation (mental re-enactment) is an automatic and integral part of language comprehension. Further support for the assumption that silent reading involves inner speech comes from an fMRI study by Loevenbruck et al. [82]. A silent reading task was examined involving different prosodic conditions. In the baseline condition, participants read a sentence in French, with a neutral prosody. In the prosodic focus condition they read the same sentence with contrastive focus on the subject constituent. In an overt mode, this would correspond to higher pitch and longer duration on the contrastively focused subject, followed by pitch compression on the post-focal constituents. When compared with the baseline, the prosodic focus condition yielded activity in the left inferior frontal gyrus, left insula, left supramarginal gyrus as well as Wernicke's area. These results suggest that silent reading with prosodic focus has clear cerebral correlates that are different from silent reading without contrastive intonation. In other words, when we silently read, we can use a marked prosodic contour, that is associated with specific cerebral correlates.

Several questions remain unresolved by recent $\mathrm{fMRI}$ studies of reading, however. For instance, it is unclear whether TVA activation during reading is early and bottom-up, or controlled by late topdown processes [80] and therefore modulated by attention or cognitive strategies. This question was recently investigated with intracranial EEG (iEEG) recording of TVA in four epileptic patients [14]. The 
cerebral region sensitive to the voice [83] was precisely localized in each of patient. Patients were instructed to perform a reading task in which attention was manipulated, by means of the Nobre et al [86] paradigm. High-Frequency 'gamma' Activity (HFA), between 50 and $150 \mathrm{~Hz}$ was analysed. HFA is considered as a reliable physiological marker of neuronal activity at the population level, and is a general index of cortical processing during cognition [87]. The results not only showed that speech perception and silent reading activate the same regions in the auditory cortex (the TVA regions) as previously suggested by Yao et al. [80], but also, that the neural response to written words in TVA is strongly modulated by attention. Previous studies by Kurby et al. [77] and Alexander and Nygaard [76] have suggested that the inner voice activation is mostly modulated by attention. Perrone-Bertolotti et al. [14] provide electrophysiological evidence for this suggestion. TVA activity was increased during attended compared to unattended words reading. This attentional effect was observed late in time, around 400 and $800 \mathrm{~ms}$ after stimulus onset. These results suggest first, that AVI or inner speech are not an automatic process occurring systematically in response to written words, and second, that TVA enhancement activity during silent reading is the result of top-down attentional control. Furthermore, the authors found that during attentive reading auditory and visual areas do not react conjointly. A lag of 700-800 ms, approximately, was observed between the activations of the visual and auditory regions. The auditory cerebral activity was late compared with the visual cerebral activity, suggesting that the inner voice during reading could be listened to as an echo. These results suggest that the rich and seemingly coherent audiovisual experience of reading arises from a heterogeneous amalgam of asynchronous neural responses. Finally, this study suggested that the high frequency [50-150 Hz] gamma band can be used not only to monitor attention during reading but also to monitor inner speech generation (see also [88]). It must be noted however, that reading is not systematically associated with inner speech, even when attention is high. Levine et al. [13] have reported the case of a man who abruptly became mute. He was unable to speak to himself and unable to appreciate the phonological structure of words. He relied on visual imaging to perform calculation and verbal short-term recall. Although this patient lacked inner speech, his reading abilities were preserved and reading comprehension was far above average.

To sum up, inner speech during reading has clear behavioural and cerebral correlates. Silent reading is modulated by the knowledge of the presumed author's speaking speed, by the talker's voice familiarity, by the reader's regional accent. Silent reading can generate auditory verbal imagery, which is shown by TVA activations. Silent reading can include prosody processing regions, as shown by differing patterns of activation during silent reading with different prosodic specifications. But inner 
speech during reading seems to be modulated by attention and is not always necessary, as shown by a case report of a patient able to read without inner speech. Thus, the little voice in our head during reading is not present all the time.

\subsection{Inner speech and writing}

Writing has long been considered to be entirely dependent upon spoken language knowledge and processes, an assumption that has been referred to as the 'phonological mediation hypothesis' (see e.g [89-91]). Writing engages different levels of processing such as idea generation, retrieval from semantic memory, syntactic processing, editing processes, organizing sequences of words into sentences and accessing graphemic forms. It is debated whether the transformation of lexical to graphemic forms involves inner speech or not. According to the phonological mediation hypothesis, the spoken form of a word must be retrieved to access the graphemic form, therefore inner speech should accompany writing. Evidence for this hypothesis comes from lesion studies showing that impairments in spoken language are associated with impairments in written language production (e.g. [92]). Further evidence is found in children studies. When children are asked to write with the mouth open or the tongue held between the teeth, writing errors greatly increase [92]. A more recent study examined 293 preschool children who were administered an assessment battery that included measures to examine oral language and writing. The results show that as early as preschool, children with weaker oral language skills lag behind their peers with stronger oral language skills in terms of their writing-related skills [93]. An alternative view holds that orthographic forms can be accessed from abstract lexical knowledge directly, without necessary phonological mediation. Several patient studies that have reported dissociations between writing and speaking impairments are consistent with this view. Levine et al. [13], cited above, have reported the case of a patient who lacked inner speech, yet his reading ability was preserved, as well as his written expression. Rapp et al. [94] presented the case of a neurologically impaired individual who was often unable to provide the correct spoken name of an object although he was still able to write its name correctly (see also [61]). Although these findings seem to corroborate the hypothesis that orthographic lexical forms can be accessed without the mediating role of phonology and without inner speech, the patient in Levine et al.'s study had exceptional visual imagery skills (before the stroke) that allowed him to compensate for his inner speech impairment, as suggested by the patient himself. It is possible that inner speech during reading was associated with strong visual imagery before the stroke and that this learned connection between visual imagery and reading helped him recover reading after the stroke. The recent study of a congenitally speechless child (oral apraxia) is more conclusive [95]. This study showed that, despite his 
inability to reproduce any oral or articulatory movement, and his inability to produce any sound, even in the form of a rudimentary cry, the child had normal reading and writing skills. He also had normal verbal memory and meta-phonological skills. It is difficult to imagine that this child had inner speech, in oral form at least. These findings suggest that speech output, and oral inner speech, is not a necessary condition for the acquisition of writing.

\subsection{Modalities of inner speech: inner signing and voice-hallucinations in deaf people}

Non-hearing people often communicate using sign languages. Sign languages combine hand shapes, orientation and movement of the hands, arms or body, and facial expressions to express a signer's thoughts. Behavioural studies have suggested that the process equivalent to inner speech in deaf signers may involve internal representation of signs rather than phonological representation (in the articulatory and/or acoustic domain). Bellugi et al. [96] compared short-term memory for words in hearing and deaf participants whose native language is American Sign Language (ASL). Lists of signs of ASL were presented to the deaf participants. A comparable short-term memory experiment for spoken words was presented to hearing participants. Recall was written in both groups. Intrusion errors made by deaf subjects to signs paralleled the phonologically-based errors made by hearing subjects. Precisely, even though the responses were in written English words, multiple intrusion errors did not at all reflect, as they did for hearing subjects, the phonological structure of the words. They did not reflect iconic visual properties either. Instead, intrusion errors made by deaf subjects were based on formational properties of the signs themselves. They reflect specific organizational principles of ASL. These findings suggest that short-term verbal memory, and therefore inner verbal production, is not restricted to the speech mode and can include a sign mode. Further examination of verbal working memory in deaf signers has shown analogy with working memory in speech. Wilson and Emmorey [97] have demonstrated a sign length effect in ASL based working memory that parallels the word length effect for spoken language. They have also found that manual articulatory suppression disrupts working memory for signs, just like oral articulatory suppression disrupts working memory for speech. Wilson and Emmorey suggest that verbal working memory develops in response to language experience, regardless of sensorimotor modality. These findings further argue that sign language seems to be stored in working memory on the basis of its articulatory rather than iconic visual properties. Moreover, they further argue for the multimodal quality of inner verbal production. McGuire and colleagues [98] conducted PET scan studies examining covert speech articulation in hearing participants and covert sign articulation in deaf participants. They found that internal generation of British Sign Language 
sentences by deaf participants activated the left inferior frontal cortex, rather than visuo-spatial areas. The activated regions corresponded to that observed during covert English sentence production in hearing individuals. This suggests that "inner signing" recruits similar regions to inner speech. Therefore, inner verbal production does not appear to be modality specific and might equally be engaged by speech or sign. Moreover, inner processes in speech and sign may share a common cerebral substrate.

The study of voice-hallucinations in deaf signers provides further insight into the perceptual characteristics of inner language in congenitally deaf individuals. Auditory verbal hallucinations in hearing individuals have been related to inner speech (see section 5.3). In a thorough review of the literature on hallucinations in deaf people, Atkinson [99] speculated on the mechanisms underlying voice-hallucinations in both hearing and deaf people. According to her review, around half of all deaf people diagnosed with schizophrenia report experiencing 'voices', a prevalence rate similar to auditory verbal hallucinations (AVH) in hearing people with schizophrenia (see section 5.3). Although the report of auditory hallucinations in prelingually deaf patients may seem at first incongruous, the careful examination of literature data by Atkinson has shed new light on the phenomenon of hallucination and inner vocal processes. Voice-hallucinations in deaf people cover a broad range of phenomena. Their descriptions by the deaf patients themselves are less clear-cut than AVH in hearing patients. AVH in hearing patients are reported as showing variations in loudness, pitch, intonation, whereas deaf patients cannot give similar descriptions of the auditory quality of their hallucinations, even when they specifically report hearing a voice. But they are able to relay the message "heard", the identity of the 'voice', and its affective content. Voice-hallucinations also cover such phenomena as the sense of being signed or fingerspelled to, somatic perceptions like vibrations felt within the body, and visual hallucinations. Atkinson has summarized several interpretations. The first is that the term 'hearing a voice' is misleading and that these voice-hallucinations have no auditory property at all. They could be due to a methodological bias due to the audiocentric way the research interviews are designed. And they could be due to misconception of voices by congenitally deaf people. The second is that 'voices' in deaf hallucinators are messages, communications, without a clear perceptual agent. The third one is that these hallucinatory experiences are visual or motor perception of the spoken or signed articulations of the 'voice' agent. Deaf hallucinators might sense a vague percept of hands or mouth articulating the 'voice' messages received. It is still an open question whether these hallucinatory images are visual or motor (kinaesthetic) or a combination of both. Another one stems from the fact that very few people are born totally deaf and some profoundly deaf people who use spoken language 
(and who use amplification to exploit residual hearing) may have some awareness of the sounds that accompany their perception or production of speech. These people may in fact well form representations of the auditory consequences of their articulation or that seen in others. Therefore Atkinson's review provides insight into how inner spoken and sign languages may be represented in the mind and suggests that inner language may include (and perhaps integrate) multimodal sensory information, in the auditory, motor, kinaesthetic and visual domains.

\subsection{Summary so far}

Examining the phenomenology of inner speech shows that many similarities exist between inner and overt speech, but that many differences are also manifest. Overt speech is not just inner speech with added motor processes. Greater activation in auditory areas, for instance, is associated with the perception of one's own overt speech. And inner speech seems to recruit some cerebral regions that are not recruited in overt speech. Some of these activations can be attributed to inhibition of overt responses or response conflict. Nevertheless, inner speech can still be seen as a truncation of overt speech, but the level at which the speech production process is interrupted needs better characterisation. There could even be different instantiations of inner speech. Abstract instantiations would involve the activation of abstract linguistic representation, with little acoustic or phonetic features, and could be referred to as the 'language of the mind' or "thinking in pure meaning". These abstract representations could be the essence of verbal mind wandering. It could also be the inner speech used by persons who stutter and who introspect that they are fluent in inner speech. Concrete instantiations would be more flexible, being either phonological (more abstract) or phonetic (more concrete). They could correspond to wilful inner speech generation. Other instances when inner speech may occur are during reading and writing. Inner speech during reading has clear behavioural and cerebral correlates. But it seems to be modulated by attention and is not always necessary, as shown by a case report of a patient able to read without inner speech. During writing, although oral inner speech may be involved, it is not necessary. Inner language and hallucinations properties in deaf people suggest that inner language may include (and perhaps integrate) multimodal sensory information, in the auditory, motor, kinaesthetic and visual domains. They also further demonstrate that inner speech manifests itself with different degrees of abstraction. Deaf hallucinators who mention they hear 'voices' may in fact be experiencing an abstract form of inner speech. We speculate that this abstract inner speech may correspond to amodal representations, construed in associative brain areas. Other deaf hallucinators who mention visual or tactile sensations might be experiencing a more concrete form of inner speech involving visual and/or kinaesthetic and/or motor 
representations. Further behavioural and neuroimaging studies are necessary to better characterize these different manifestations of inner speech.

\section{The influence of inner speech on cognitive performance}

The role of inner speech in parallel attentional tasks raises substantial questions. Why do we engage in inner speech? What is the advantage of inner speech in our everyday life? Can we better explain why deliberate inner speech helps us in task-switching or problem-solving? And does excessive self-reflecting prevent us from doing some cognitive tasks?

\subsection{Inner speech and task-switching}

Inner speech is not usually associated with executive control processes. Inner speech is often considered instead as playing a peripheral passive role in the storage of information in short-term memory $[57,100]$. According to Baddeley's [101] initial model of working memory, inner speech (also called subvocal speech or articulatory rehearsal) is involved in the phonological loop that is dedicated to the storage, processing and maintenance of verbal information, under the supervision of the central executive system. According to this view, action is mostly under the control of the central executive system and inner speech has only a passive role, in the service of memorization. In the past, however, Vygotsky [2] and Luria [102] have claimed an active regulatory function of inner speech. They argued that inner speech should not be regarded simply as verbal memory. In the same vein, it has been suggested that verbalizing (overtly and covertly) allows the stabilization of abstract ideas in working memory, making them available for inspection [2, 103, 104]. Baddeley, Chincotta, and Adlam [105] in fact revised Baddeley's initial concept of inner speech. They found that articulatory suppression (overtly reciting a familiar word sequence, such as days of the week) affected performance during switching arithmetic tasks (regular switching between addition and subtraction). They concluded that articulatory suppression interferes with the retention of the switching program by disrupting the phonological loop. They suggested that the phonological loop plays a role in switching between arithmetic tasks and therefore has a more active and executive role than initially claimed. This conclusion is in line with Miyake and Shah's review of working memory models [106], which argued that phonological loop should not be viewed simply as a temporary memory or rehearsal device in the service of pure temporary memorization. 
The role of inner speech in task-switching was further examined by Emerson and Miyake [107]. Emerson and Miyake raised the question of the role of inner speech in task-switching performance: why is inner speech useful in task-switching? They specifically addressed whether the switching impairment associated with articulatory suppression goes beyond the general decrement observed when two tasks are performed simultaneously. They carried out a dual-task experiment in which participants performed switching arithmetic tasks in parallel with either articulatory suppression, foot tapping or without any secondary task. They observed that articulatory suppression caused a significant increase in switch cost (time per operation switch) but not foot tapping. This led them to conclude that the increase in switch cost caused by concurrent articulatory suppression cannot be solely due to performing any two tasks at the same time. They suggested that inner speech could be recruited to implement a verbally-based self instruction (covertly saying to oneself "add, subtract, add, subtract"). To examine whether inner speech is involved in retrieving and activating a phonological representation of the upcoming task, they also manipulated the cue type (presence or absence of symbolic external cues), the task difficulty and the number of tasks to be switched. They found that the presence of explicit symbol cues reduced the detrimental effect of articulatory suppression. In contrast, neither the task difficulty nor the number of switches affected the magnitude of the articulatory suppression effect. Their results provide strong support for the hypothesis that inner speech serves as a reliable internal self-cuing device that helps retrieve and activate the phonological representation of the upcoming task goal. These authors highlight the valuable role of inner speech in endogenous control (when the availability of external cues signalling what task to perform next is limited) and hence in improving performance. They suggest that their results are consistent with the view that inner speech plays a role in executive control and with earlier claims about the regulatory function of inner speech [2].

\subsection{Inner speech and problem-solving}

The benefit of using inner speech is not exclusive to task-switching. Inner speech has also been shown to play a role in problem-solving. Sokolov [9] reviewed studies in which tasks such as mental arithmetic and word repetition involved speech muscle contraction, suggesting that language accompanies problem-solving. Hermer-Vazquez et al. [108] found that verbal shadowing (but not nonverbal rhythmic shadowing) prevented participants from performing a spatial-localisation task. This study suggests that language supports non-verbal cognition. Dunbar and Sussman [109] showed that when asked to perform the Wisconsin Card Sorting Test (WCST, a non verbal test used as a measure of frontal lobe or executive functioning) in parallel with articulatory suppression, participants committed 
more errors. Similarly, Lupyan [110] examined performance during an object categorization task, which required isolating perceptual dimensions (finding the odd-one-out, with respect to colour or size) in two conditions of interference. Verbal interference selectively impaired judgments involving the isolation of perceptual dimensions while sparing global thematic judgments. Visuospatial interference produced a slight non-selective decrement in accuracy (with no corresponding increase in reaction times RTs). These results provide support for the hypothesis that certain types of non-verbal categorization may depend on language in some way, even when no verbal response is required. The author suggests that verbal interference impairs lexical representations from feeding back onto lower level (e.g. perceptual) representations. Interestingly, decrements in performance due to verbal interference were observed in both complex switching tasks and simple perceptual tasks [107, 111, $112]$.

Studies of patients with aphasia can also shed light on the relationship between inner speech and problem-solving. Some aphasia studies show that non-verbal reasoning performance is related with the degree of language impairment [113-116]. The relation between inner speech and problem-solving is still debated, however. It has been argued that problem-solving deficits in aphasia patients could be due to the coincidental encroachment of lesions in nearby regions crucial for cognition [117]. To examine this hypothesis, Baldo et al. [118] investigated the effect of language on problem-solving with the WCST within a large series of stroke patients (with different degrees of language impairment). They found a significant correlation between performance on the WCST and language proficiency in stroke patients. They also replicated the finding that normal participants are significantly impaired on the WCST under conditions of articulatory suppression, relative to baseline.

Therefore, deliberate inner speech seems to help problem-solving. Covert verbalization could improve performance by improving self-regulation as well as by activating relevant lexical representations. Furthermore, in more demanding situations, non-deliberate inner speech (verbal mind wandering) seems to enhance attention. Attentional blink is the impaired ability to identify the second of two visual targets presented in close succession [119]. A paradoxical finding by Olivers and Nieuwenhuis [120], is that attentional blink is reduced (detection of the second target is improved) when observers are concurrently engaged in distracting mental activity, such as free-associating on a task-irrelevant theme (like thinking about their holiday plans). This suggests that taking away (targetfocused) attentional resources via mind wandering may actually be beneficial, rather than detrimental. Baars [121] also argues that mind wandering, even if it appears irrelevant, unwanted, or intrusive, may still play an important adaptive role in life-relevant problem solving and learning. 
Together, these findings suggest that deliberate inner speech (voluntary verbal thought generation) as well as unconstrained inner speech (verbal mind wandering) both may improve problem-solving.

\subsection{Inner speech and rumination}

On the other hand, it has been shown that excessive negative self-reflecting (rumination) alters cognitive performance in depressed or dysphoric patients [122]. It is not clear whether the cognitive impairments observed are a cause or a consequence of rumination, however. Several studies showed that individual differences in working memory capacity are related to the ability to intentionally suppress intrusive thoughts [123-125]. These studies suggest that a higher working memory capacity is related to having fewer intrusive thoughts (see also [126]). This is also in agreement with the recent proposition of Hofmann et al. [127] who outline how executive functioning may subserve successful self-regulation and how a higher working memory may help to suppress ruminative thoughts. It still remains to be understood why excessive negative inner speech impairs performance whereas more controlled and positive inner speech improves cognitive performance.

The 'gateway hypothesis' of rostral prefrontal cortex developed by Burgess and colleagues ([128]; see also [129]) offers a way into addressing this issue. The hypothesis maintains that rostral PFC supports mechanisms that enable us to attend either to environmental stimuli or to self-generated representations (i.e. the 'thoughts in our head'). It is suggested that a 'supervisory attentional gateway' (SAG) system effects (through influence of attending behaviour) the coordination of stimulusindependent ( $\mathrm{SI}$ ) and stimulus-oriented (SO) cognition. Comparing brain activity in tasks involving various types of inner speech and various SI- and SO- cognitive performance might help better understanding the support or interference of inner speech with cognition. The rostral PFC is a good candidate for a mechanism that detects when inner speech (verbal mind wandering) needs to be turned down to shift the attention back to the environment.

\section{Agency during inner speech}

Another crucial question deals with agency in inner speech. How do we know that the inner voice that we hear is self-generated and not produced by another person? We process our inner speech auditorily, our inner voice has a timbre and a pitch (we can hear whether it is a question or a statement) and we can even detect errors in our own inner speech. We can imagine someone else speaking and we then hear his/her voice. So how do we not confuse these inner voices with external voices? What 
makes us able to distinguish between self- and other-generated auditory sensations? Which cerebral structures or networks are recruited for self/other monitoring during inner speech?

\subsection{Agency within predictive modelling of inner speech}

It has been suggested that inner speech may share some properties with motor actions [59, 130, 131]. Although the hypothesis that "inner speech is a kind of action" is still a matter of debates (see e.g. [132]) it has led to interesting theoretical modelling, via the motor control framework [133] and typically via the 'predictive model' (also called 'comparator model'). In this framework, it is claimed that the brain uses forward modelling to predict the consequences of action [134, 135]. When motor commands are sent to the motor system to achieve a particular intended end-state, an efference copy is issued in parallel. This efference copy (see [136]) is used to compute a prediction (corollary discharge) of the sensory outcome of the motor plan (see Fig. 1). Forward modelling (i.e. feed-forward control or with internal feedback) in the control of movement has been extended to speech (e.g. $[133,137,138])$ and also to inner speech [59, 139-141].

The predictive model has two advantages. First, errors can be detected before the arrival of the sensory feedback. Motor commands can be adjusted online to reach the intended goal, which makes for smooth motor actions (see [133]). Secondly, the predictive system provides information about the source of sensations, or agency. In other words, the predictive model allows distinguishing the selfgenerated speech and the externally generated speech by means of an efference copy. It is also suggested that if the actual sensory feedback matches the predicted outcome then self-authorship is experienced [140]. Frith claims that a defective predictive system could explain why an action may be experienced as controlled by another in the 'delusion of control' symptom: if the predicted sensory outcome does not match the actual sensory feedback then some external influence must have been at work. A further feature of the predictive model is that when actual and predicted states match, the sensory effect of the motor act is cancelled, attenuating it perceptually compared with identical stimulation that is externally produced [142]. This suggests that a modulation/attenuation of sensory cortex activity occurs when an action is self-initiated.

Insert Figure 1 about here 
Implication of an efference copy mechanism in inner speech control is supported by several neuroimaging studies demonstrating a frontal modulation of the temporal regions during inner speech production $([139,143]$ for silent speech; without vocalization but with articulation; [144]). Ford and Mathalon [139] conducted an ERP study focused on the auditory cortex. Their results show that the N1 component generated in auditory cortex was reduced during talking (overt and covert) conditions compared to a baseline condition. These results provide neurophysiological evidence in support of a dampening of auditory cortex during self-generated speech: corollary discharge may signal speech reception areas that speech-related activations are self-generated. In the same study, to provide direct evidence that the auditory cortex activity modulation is the result of corollary discharge from the frontal lobe, they performed an EEG coherence analysis. The results suggest that interdependence between frontal speech production areas and temporal speech reception areas is more important during talking that during listening.

Nevertheless, we suggest that this application of the forward modelling to inner speech is problematic. As questioned by Frith [145] himself, what are the actual sensory consequences of inner speech? Inner speech generates neither kinematics nor auditory sensations, since it is internally generated. So the comparison between the predicted state and the actual state is irrelevant in the case of inner speech (see Fig. 1). Two alternative interpretations have recently been suggested ([146], in press). First, it is plausible that during inner speech, motor commands are generated, and sent to appropriate speech muscles. Inhibitory signals may be sent in parallel to prevent the intensity of the motor commands from reaching a sufficient threshold for movements of the speech organs to occur. But even though the speech organs may not move during inner speech, the presence of motor commands in the speech muscles could slightly increase muscle tension and could correspond to detectable proprioceptive feedback. This suggests that in the instance of inner speech production, the actual sensory feedback would in fact be a proprioceptive sensory feedback. Another interrogation surfaces then, about how a comparison can take place between a rich predicted somatosensory feedback and a poor actual proprioceptive feedback. This has yet to be investigated.

The second possible interpretation is that during inner speech, motor commands may be sent to the motor system, but they would be inhibited and hence irrelevant since no auditory output would be produced. A copy of these motor commands would also be sent to the forward model, the output of that being the auditory voice we hear in our head (inner speech has sensory qualities and can be 
associated with rich suprasegmental acoustic representations, c.f., [81]). Rapin et al. [146] suggest that the relevant comparison for agency monitoring during inner speech is not that between predicted and actual sensory states but instead, the one between intended and predicted states (see Fig. 1).

\subsection{Evidence for "inner speech is an action"}

Electromyographic (EMG) signals are electrical potentials arising from muscle movements/contractions. They originate from the motor cortex when the brain sends action potentials along appropriate nerve tracts. They transmit to the muscle groups resulting in contractions of the muscle fibers. If the "inner speech is a kind of action" hypothesis is true, it can be predicted that EMG activity be present during inner speech. EMG activity has been detected in the speech musculature during verbal imagery and covert rehearsal $[9,147]$. McGuigan and Dollins [148] collected EMG data showing that the lips are active when silently reading the letter "P", but not when reading "T". Reciprocally, the tongue was active only for silently reading " $T$ ". Livesay et al. [149] observed lip EMG activity in an inner recitation task, but not in a visualization task. Shimizu and Inoue [150] suggested that speech in dreams may be accompanied by EMG activity in speech muscles. Max [151] investigated activity in the flexores digitorum, a muscle in the forearm that flexes the fingers, in 18 deaf participants during several mental tasks such as silent reading, memorizing, implicit repetition of verbal materials, implicit rearrangement of mixed sentences, counting silently. They observed that these tasks were accompanied by an increase in EMG activity in the flexores digitorum compared to a relaxation baseline in 84 of the cases. EMG activity in a control muscle (in the leg) did not vary as much. Sixteen hearing participants were also tested. The EMG activity in their arm muscle did not vary as much as that of the deaf participants (31\%) and the average amplitude of the EMG signal was much smaller. EMG activity was recorded in their tongue, but the results are inconclusive as most hearing participants failed to achieve a relaxed state to a degree comparable with that of the arm.

As noted by Vanderwolf [152], the source of this low amplitude EMG activity (during inner speech or inner signing) has not been elucidated. It has been suggested that part of it arises from intrafusal muscle fibers [153]. A recent examination of hand-related motoneuron activity has shown that a mental arithmetic task affects the rate and variability of the tonic discharge of motor units [154]. The increases observed in hand EMG activity were consistent with the modulation of the motor unit discharge rate induced by mental arithmetics. This finding suggests that mental arithmetic may influence the state of the motor system, including its most peripheral spinal component, i.e. the motoneuron. 
To summarise, these findings suggest that EMG activity is present in speech muscles during inner speech and are coherent with the view that "inner speech is a kind of action". Motor commands issued during inner speech could modulate motoneuron activity in the lips and could result in the observed slight increase of EMG activity.

Further evidence for the notion that "inner speech is a kind of action" come from neuroimaging and transcranial magnetic stimulation (TMS) studies. There is evidence for motor cortex (precentral gyrus) activation during inner speech [155]. Fadiga et al. [156], using TMS, have shown that during listening of words involving tongue movements, there is an increase of motor-evoked potentials recorded from the listeners' tongue muscles. Inhibition of left inferior frontal cortex by repetitive TMS (rTMS) has been shown to provoke speech arrest [157, 158]. Aziz-Zadeh et al. [159] have shown that inner speech arrest may be induced by rTMS of either a left posterior (motor) or a left anterior (inferior frontal gyrus) site. They conclude that motor cortex is thus essential to language elaboration, even when motor output is not required.

These findings support the view that inner speech is a kind of action, namely motor imagery of overt speech. It has been suggested that motor imagery (of body actions) involves motor cortex with inhibition of execution occurring further downstream from the cortex (e.g. [160, 161]). A recent review by Shibasaki [162] provides further evidence of the motor cortex activation during motor imagination. It suggests that voluntary motor inhibition involves the recruitment of inhibitory and/or negative motor areas and the activation of inhibitory interneurons at the spinal cord. We suggest that inner speech may similarly involve speech motor cortex. A complex mix of activation in motor cortex and inhibitory motor areas may result in the presence of residual EMG activity in orofacial muscles.

The presence of EMG activity during inner speech has an alternative interpretation however, in agreement with mirror system or interaction theories of speech production/perception [156, 163], or with the Motor Theory of speech perception [164]. The motor activity observed during inner speech could simply be an epiphenomenon of a sensory (auditory) processing of the inner voice. Any motor cortex activity or EMG activity recorded during mental verbal generation could in fact reflect the motor system resonance with the auditory images evoked by the inner speech generation.

More behavioural and neuroimaging studies, providing detailed connectivity, coherence and timing information, are needed to disentangle between the predictive modelling account and this alternative interpretation. 


\subsection{A case of impaired inner speech}

Among the most typical symptoms of schizophrenia are auditory verbal hallucinations (AVH), affecting $50 \%$ to $80 \%$ of the patients [165]. AVH or "hearing voices" can be considered as speech perceptions in the absence of a relevant external acoustic input. Patients report hearing voices, mostly giving them orders or instructions. Inner speech was first incriminated in the pathogenesis of AVH by Gould ([166]; followed by [167, 168]), who showed an increase in EMG activity in the lower lip and chin during AVH. However, the direct responsibility of inner speech in AVH has been debated [169], some suggesting that when AVHs are not subvocalized (accompanied by subtle articulatory movements) they would not systematically involve speech muscle activity [170]. In a recent study ([146], in press), surface EMG data were collected during covert AVH (without articulation) and rest in 11 schizophrenia patients. The results showed that lower lip EMG activity is significantly greater during AVH than during rest, which could mean that speech motor commands are generated during AVH. Furthermore, neuroimaging studies of $\mathrm{AVH}$ in patients with schizophrenia suggest an involvement of a frontal and temporal language network including auditory cortex, and it has been suggested that AVH and inner speech are associated with overlapping neural networks (e.g., [131, 171, 172]).

Many theoretical models have been proposed to explain AVH in schizophrenia and its relationship with inner speech (see e.g. [173] or [174] for reviews). It has been suggested that a failure in the efference copy system could underlie auditory verbal hallucinations (AVH), with self-initiated covert verbal actions experienced as originating from an external cause [59, 130]. Seal et al. [175] and Jones and Fernyhough [131] have tried to apply the predictive model of motor actions to inner speech and $\mathrm{AVH}$. They suggest that, during $\mathrm{AVH}$, because of a distortion or absence of a predicted state, the actual sensory consequences of the inner speech are not cancelled out. Either because of attributional biases [175], or because the emotion of self-authorship is not felt [131], inner speech is then experienced as other-generated. Specifically, in schizophrenia patients, the corollary discharge from frontal areas where verbal thoughts are generated fails to alert the auditory cortex that they are selfgenerated, leading to the misattribution of inner speech to external sources (cf. also $[139,176,177])$. Ford and Mathalon [139] showed that in schizophrenia patients, the dampening effect of auditory cortex during self-generated overt or inner speech did not operate, reinforcing the hypothesis that corollary discharge dysfunction may lead to misperceptions that speech-related activations have an external source (see also [178]). 
Some researchers have recently focused on the difference between AVH and inner speech in non-clinical hallucinators. If AVH are most commonly reported in schizophrenia patients [179], they can also be present in non-psychiatric participants $[180,181]$. When comparing inner speech and AVH, nonclinical hallucinators are an interesting population to examine, to study the phenomenon of AVH in a relatively pure form, without concomitant factors related to psychosis or medication. Linden et al. [182] have argued that the essential distinction between AVH and inner speech is related to subjective control: AVH occurs spontaneously, while wilful inner speech occurs under volitional control. To examine the hypothesis that $\mathrm{AVH}$ and inner speech may involve different network dynamics, they evaluated the timing of activation onset between cerebral regions involved in action planning an ideation (supplementary motor area) and auditory processing (temporal voice area, TVA, see above) during $\mathrm{AVH}$ and inner speech in non-psychiatric hallucinators. Their results revealed earlier activation of the auditory regions with respect to action planning regions in AVH compared with active inner speech. During inner speech, activity in the SMA preceded temporal lobe activity. According to Linden et al., this sequence of brain region activations conforms to a model in which ideation and planning of inner speech precede the subsequent perceptual experience (human voice area in the superior temporal sulcus, STS). During AVH, however, SMA and STS were activated simultaneously. Linden et al. have interpreted this synchrony as a lack of sensory suppression during preparation of speech in nonclinical AVH. The fact that the primary auditory cortex, and typically the voice area, was also more activated during AVH further supports this account.

These findings are in line with a recent fMRI study of inner speech in schizophrenia patients by Rapin et al. [63]. Since AVHs occur out of the control of the patient, experimental manipulation of control over verbal material is important for understanding the neural correlates of hallucinations. Rapin et al. [63] implemented such a manipulation by comparing wilful inner speech (covert word definition generation, high control) to speech perception (low control) conditions. The results revealed hyperactivity in a temporal-frontal network of speech-related auditory and motor regions for (hallucinating and non-hallucinating) schizophrenia patients relative to healthy controls during both inner speech and speech perception. In a follow-up study [183] including schizophrenia, bipolar and healthy participants, hyperactivity correlated significantly with hallucinations during speech perception only, i.e. when control processes were not engaged. Lavigne et al. [183] suggest that hallucinations should not simply be considered inner thoughts with added perceptual qualities, as control processes activated during covert verbal generation can serve to normalize the hyperactivity of activity observed in speech perception. 
Along this line, the 'gateway hypothesis' described above (section 4.3) offers an interesting explanatory framework. As mentioned above (section 3.2), recent research suggests that the DMN is hyperactive in schizophrenia (e.g. $[63,184])$. We speculate that the supervisory attentional gateway system may also dysfunction in patients with schizophrenia. This could explain the frequent occurrence of unbidden inner speech, which, because of a parallel corollary discharge dysfunction, would be attributed to an external source. It is of note that inner speech dysfunction is one of the many theoretical accounts of the understanding of $\mathrm{AVH}$. As the present review concerns inner speech, we decided to focus on this particular theory. Yet, some alternative accounts propose that AVH are unintentionally reactivated memories. AVH would be related to overactive auditory memory traces $[[185,186]$ and would be caused by misremembered auditory memories of speech [187-189].

To sum up, an influential theoretical account of auditory verbal hallucination claims that a deficit in inner speech monitoring would cause verbal thoughts to be perceived as external voices. The account is based on a predictive control model, in which verbal self-monitoring and agency are implemented. This model offers a mechanism by which we know that the inner voice that we hear is self-generated and not produced by another person. Other accounts of AVH have been proposed, involving auditory memory, and the role of inner speech in AVH is still debated. Yet common to most of the neuroimaging studies of $\mathrm{AVH}$, inner speech and inner reading is the finding that functional connections and modulations between frontal and temporal regions seem to be at play when we monitor our own inner speech or inner reading.

\section{Conclusion}

An impressive host of findings on inner speech has emerged these last fifty years. T able summarizes main findings and questions still to be solved. The current state of the art suggests that although many behavioural similarities exist between inner and overt speech many differences are also manifest. Neurally, overt speech is not just inner speech with added motor processes. Greater auditory cortex activation is associated with the perception of one's own overt speech, whereas inner speech recruits inhibitory regions that are not recruited in overt speech. Nevertheless, inner speech can still be seen as a truncation of overt speech, but the level at which the speech production process is interrupted needs better characterisation. Different instantiations of inner speech are also manifest. Abstract instantiations would involve little acoustic or phonetic features, and could be referred to as the 'language of the mind' or "thinking in pure meaning". These abstract representations could be the essence of verbal mind wandering or of inner speech in persons who stutter. Concrete instantiations would be more flexible (phonological or phonetic) and would be associated with wilful inner speech 
generation. Other instances when inner speech may occur are during reading and writing. Inner speech during reading has clear behavioural and cerebral correlates. But it seems to be modulated by attention and does not seem necessary. Similarly, during writing, although oral inner speech may be involved, it is not necessary. Inner language properties in deaf people suggest that inner language may integrate multimodal sensory information, in the auditory, motor, kinaesthetic and visual domains. Voicehallucinations in deaf people further demonstrate that inner speech manifests itself with different degrees of abstraction. We speculate that this abstract inner speech may correspond to amodal representations, construed in associative brain areas. Further behavioural and neuroimaging studies are needed to better describe these different manifestations of inner speech.

Inner speech plays a crucial role in executive control. It is helpful in working memory, in taskswitching, in problem-solving. In addition, deliberate as well as spontaneous inner speech are involved in attentional enhancement. Inner speech in its various manifestations strongly interacts with executive function. Deeper knowledge on how inner speech (be it voluntary or free) enhances cognitive performance could help healthy people with high concentration needs.

Insert Table 2 about here

Excessive negative inner speech or rumination can impair cognitive performance. Deficits in selfmonitoring during inner speech could underlie AVH. Further studies could help explain the mechanisms inducing mental ruminations (excessive negative inner speech) and auditory verbal hallucinations (disruption in self-monitoring), two disorders of inner speech. A better understanding of the cerebral network and brain dynamics engaged in healthy inner speech has potential implications for remediation therapy in patients with inner speech disorders. Using EMG or EEG recordings of their own inner speech, schizophrenia patients could assess the number of self-given orders or insults for instance and learn to prevent them from occurring via neuro-bio-feedback training, together with orofacial relaxation techniques. Patients with anxiety disorders or depression, suffering from mental rumination, could similarly train to reduce their excessive negative inner speech. Attention-deficit disorder therapy could also benefit from more knowledge on excessive mind-wandering reduction. 
Several theoretical questions remain to be resolved, however. It is unclear whether cerebral activity during inner speech originates from frontal (speech products) rather than temporal (speech percepts) regions? Where do auditory percepts during inner speech come from? How do we produce inner speech with someone else's voice? Do we have a predictive model for each of the voices we know? What are the mechanisms that may induce inner speech dysfunction? Concerning inner speech during silent reading, it is unclear whether inner speech perception improves reading performance. Another open question is whether the brief temporal cortex activation during unattended reading is sufficient to lead to a conscious experience of an inner voice. A further approach to investigate the nature of inner speech might be to evaluate inner speech production and perception during dreaming. Also, to further examine the emergence of inner speech during development could improve our knowledge of the relationship between overt and inner speech and may provide strategies to improve learning processes during childhood.

Although issues addressed in this review are far from resolved, we believe that the host of studies combining subjective experience and objective neuronal data may be helpful to better describe the little voice inside our brain. We propose that our knowledge of inner speech will benefit from integrative approaches including first-person subjective information and third-person objective measures, as recently suggested by Petitmengin and Lachaux [190].

\section{ACKNOWLEDGMENTS}

This work was supported by MLA ANR and by the LABEX CORTEX (ANR-11-LABX-0042) of Université de Lyon, within the program "Investissements d'Avenir" (ANR-11-IDEX-0007). 


\section{REFERENCES}

[1] Zivin G. The development of self-regulation through private speech: John Wiley \& Sons; 1979.

[2] Vygotsky LS. Thought and language. Cambridge: MIT Press; 1962.

[3] Morin A. Possible links between self-awareness and inner speech theoretical background, underlying mechanisms, and empirical evidence. Journal of Consciousness Studies. 2005;12:4-5.

[4] Morin A. Inner Speech Encyclopedia of Human Behavior. 2012;Elsevier:436-43.

[5] Heavey CL, Hurlburt RT. The phenomena of inner experience. Consciousness and cognition. 2008;17:798-810.

[6] Uttl B, Morin A, Faulds TJ, Hall T, Wilson JM. Sampling Inner Speech Using Text Messaging. Proceedings of the Canadian Society for Brain, Behavior, and Cognitive Science. Kingston2012. p. 287-.

[7] Marvel CL, Desmond JE. From storage to manipulation: How the neural correlates of verbal working memory reflect varying demands on inner speech. Brain and language. 2012;120:42-51.

[8] Baddeley AD, Hitch GJ. Working memory. London: Academic Press; 1974.

[9] Sokolov AN, Onischenko GT, Lindsley DB. Inner speech and thought. New York: Plenum Press 1972.

[10] Morin A, Michaud J. Self-awareness and the left inferior frontal gyrus: Inner speech use during selfrelated processing. Brain research bulletin. 2007;74:387-96.

[11] Morin A. Self-awareness deficits following loss of inner speech: Dr. Jill Bolte Taylor's case study. Consciousness and cognition. 2009;18:524-9.

[12] Petkov Cl, Belin P. Silent Reading: Does the Brain 'Hear' Both Speech and Voices? Current Biology. 2013;23:R155-R6.

[13] Levine DN, Calvanio R, Popovics A. Language in the absence of inner speech. Neuropsychologia. 1982;20:391-409.

[14] Perrone-Bertolotti M, Kujala J, Vidal JR, Hamame CM, Ossandon T, Bertrand O, et al. How silent is silent reading? Intracerebral evidence for top-down activation of temporal voice areas during reading. The Journal of Neuroscience. 2012;32:17554-62.

[15] Conrad R. The chronology of the development of covert speech in children. Developmental Psychology. 1971;5:398.

[16] Jones PE. From 'external speech' to 'inner speech' in Vygotsky: A critical appraisal and fresh perspectives. Language \& Communication. 2009;29:166-81.

[17] Kohlberg L, Yaeger J, Hjertholm E. Private speech: Four studies and a review of theories. Child Development. 1968:691-736.

[18] Mani N, Plunkett K. In the Infant's Mind's Ear Evidence for Implicit Naming in 18-Month-Olds. Psychological Science. 2010;21:908-13.

[19] Ngon C, Peperkamp S. A deep look into the developing lexicon: revelations from covert picturenaming. Proceedings of the International Child Phonology Conference. Nijemegen, The Netherlands2013. p. 29-30.

[20] Agnati LF, Barlow P, Ghidoni R, Borroto-Escuela DO, Guidolin D, Fuxe K. Possible genetic and epigenetic links between human inner speech, schizophrenia and altruism. Brain research bulletin. 2012;1476:38-57.

[21] Gould SJ, Vrba ES. Exaptation-A missing term in the science of form. Paleobiology. 1982;8:4-15.

[22] Watson JB. Psychology as the Behaviorist Views it. Psychological review. 1913;20:158-77.

[23] Watson JB. Psychology from the standpoint of a behaviorist. Philadelphia: Lippincott, J. B. ; 1919.

[24] Smith SM, Brown HO, Toman JEP, Goodman LS. The lack of cerebral effects of d-tubocurarine. The journal of the american society of anesthesiologists, INC 1947;8:1-14.

[25] MacKay DG. Constraints on theories of inner speech. In: Reisberg D, editor. Auditory imagery, Hillsdale, N. J., England: Lawrence Erlbaum; 1992. p. 121-49. 
[26] Jeannerod $M$. Les troubles de la reconnaissance de soi: une approche neuropsychologique des sympômes positifs de la schizophénie. Médecine Sciences. 2003;19:621-4.

[27] Conrad B, Schönle P. Speech and respiration. Archiv für Psychiatrie und Nervenkrankheiten. 1979;226:251-68.

[28] Netsell R, Ashley E, Bakker K. The Inner Speech of Persons who Stutter. Proceedings of the International Motor Speech Conference. Savannah, Georgia2010.

[29] Oppenheim GM, Dell GS. Inner speech slips exhibit lexical bias, but not the phonemic similarity effect. Cognition. 2008;106:528-37.

[30] Oppenheim GM, Dell GS. Motor movement matters: The flexible abstractness of inner speech. Memory \& cognition. 2010;38:1147-60.

[31] Brocklehurst P, Corley M. Lexical bias and the phonemic similarity effect in inner speech. 15th Annual Conference on2009.

[32] Corley M, Brocklehurst PH, Moat HS. Error biases in inner and overt speech: Evidence from tongue twisters. Journal of experimental psychology: Learning, memory, and cognition. 2011;37:162.

[33] Geva S, Jones PS, Crinion JT, Price CJ, Baron J-C, Warburton EA. The neural correlates of inner speech defined by voxel-based lesion-symptom mapping. Brain. 2011;134:3071-82.

[34] Egger V. La parole intérieure: essai de psychologie descriptive. Paris Ancienne Libraire Germer Bailliere; 1881.

[35] Ballet G. Le langage intérieur et les diverses formes de l'aphasie. Paris: Ancienne Libraire Germer Bailliere; 1886.

[36] Dell GS, Repka RJ. Errors in inner speech. New York: : Plenum 1992.

[37] Fernyhough C. Alien voices and inner dialogue: towards a developmental account of auditory verbal hallucinations. New Ideas in Psychology. 2004;22:49-68.

[38] Indefrey P, Levelt W. The spatial and temporal signatures of word production components. Cognition. 2004;92:101-44.

[39] Price CJ. A review and synthesis of the first 20 years of PET and fMRI studies of heard speech, spoken language and reading. Neuroimage. 2012;62:816-47.

[40] Bookheimer SY, Zeffiro TA, Blaxton T, Gaillard W, Theodore W. Regional cerebral blood flow during object naming and word reading. Human Brain Mapping. 1995;3:93-106.

[41] Basho S, Palmer ED, Rubio MA, Wulfeck B, Müller R-A. Effects of generation mode in fMRI adaptations of semantic fluency: paced production and overt speech. Neuropsychologia. 2007;45:1697-706.

[42] Huang J, Carr TH, Cao Y. Comparing cortical activations for silent and overt speech using eventrelated fMRI. Human Brain Mapping. 2002;15:39-53.

[43] McGuire P, Silbersweig D, Murray R, David A, Frackowiak R, Frith CD. Functional anatomy of inner speech and auditory verbal imagery. Psychological medicine. 1996;26:29-38.

[44] Palmer ED, Rosen HJ, Ojemann JG, Buckner RL, Kelley WM, Petersen SE. An event-related fMRI study of overt and covert word stem completion. Neuroimage. 2001;14:182-93.

[45] Partovi S, Konrad F, Karimi S, Rengier F, Lyo JK, Zipp L, et al. Effects of covert and overt paradigms in clinical language fMRI. Academic radiology. 2012;19:518-25.

[46] Shergill SS, Bullmore ET, Brammer MJ, Williams SCR, Murray RM, McGuire PK. A functional study of auditory verbal imagery. Psychological medicine. 2001;31:241-53.

[47] Forn C, Venturaâ€ Campos N, Belenguer A, Belloch V, Parcet MA, Avila C. A comparison of brain activation patterns during covert and overt paced auditory serial addition test tasks. Human brain mapping. 2008;29:644-50.

[48] Shuster LI, Lemieux SK. An fMRI investigation of covertly and overtly produced mono-and multisyllabic words. Brain and language. 2005;93:20-31.

[49] Baciu MV, Rubin C, Decorps MA, Segebarth CM. fMRI assessment of hemispheric language dominance using a simple inner speech paradigm. NMR in Biomedicine. 1999;12:293-8. 
[50] Frings $M$, Dimitrova A, Schorn CF, Elles H-G, Hein-Kropp C, Gizewski ER, et al. Cerebellar involvement in verb generation: an fMRI study. Neuroscience letters. 2006;409:19-23.

[51] Owen WJ, Borowsky R, Sarty GE. FMRI of two measures of phonological processing in visual word recognition: ecological validity matters. Brain and language. 2004;90:40-6.

[52] Rosen HJ, Ojemann JG, Ollinger JM, Petersen SE. Comparison of brain activation during word retrieval done silently and aloud using fMRI. Brain and Cognition. 2000;42:201-17.

[53] Christoffels IK, Formisano E, Schiller NO. Neural correlates of verbal feedback processing: an fMRI study employing overt speech. Human brain mapping. 2007;28:868-79.

[54] Kielar A, Milman L, Bonakdarpour B, Thompson CK. Neural correlates of covert and overt production of tense and agreement morphology: Evidence from fMRI. Journal of neurolinguistics. 2011;24:183-201.

[55] Moriai-Izawa A, Dan H, Dan I, Sano T, Oguro K, Yokota H, et al. Multichannel fNIRS assessment of overt and covert confrontation naming. Brain and language. 2012;121:185-93.

[56] Vigliocco G, Hartsuiker RJ. The interplay of meaning, sound, and syntax in sentence production. Psychological bulletin. 2002;128:442-72.

[57] Sato M, Baciu M, Loevenbruck H, Schwartz J-L, Cathiard M-A, Segebarth C, et al. Multistable representation of speech forms: A functional MRI study of verbal transformations. Neurolmage. 2004;23:1143-51.

[58] Reisberg D, Smith JD, Baxter DA, Sonenshine M. " Enacted " auditory images are ambiguous; " pure " auditory images are not. The Quarterly Journal of Experimental Psychology. 1989;41:619-41.

[59] Feinberg I. efference copy and corollary discharge. Schizophrenia bulletin. 1978;4:636-40.

[60] Marshall RC, Rappaport BZ, Garcia-Bunuel L. Self-monitoring behavior in a case of severe auditory agnosia with aphasia. Brain and Language. 1985;24:297-313.

[61] Vercueil L, Perronne-Bertolotti M. Ictal inner speech jargon. Epilepsy \& Behavior. 2013;27:307-9.

[62] Pei X, Barbour DL, Leuthardt EC, Schalk G. Decoding vowels and consonants in spoken and imagined words using electrocorticographic signals in humans. Journal of neural engineering. 2011;8:046028.

[63] Rapin L, Dohen M, Loevenbruck H, Whitman JC, Metzak P, Woodward T. Hyperintensity of functional networks involving voice-selective cortical regions during silent thought in schizophrenia. Psychiatry Research: Neuroimaging. 2012;202:110-7.

[64] Fox MD, Snyder AZ, Vincent JL, Corbetta M, Van Essen DC, Raichle ME. The human brain is intrinsically organized into dynamic, anticorrelated functional networks. Proceedings of the National Academy of Sciences of the United States of America. 2005;102:9673-8.

[65] Duncan J, Owen AM. Common regions of the human frontal lobe recruited by diverse cognitive demands. Trends in neurosciences. 2000;23:475-83.

[66] Barron E, Riby LM, Greer J, Smallwood J. Absorbed in Thought The Effect of Mind Wandering on the Processing of Relevant and Irrelevant Events. Psychological science. 2011;22:596-601.

[67] Mason MF, Norton MI, Van Horn JD, Wegner DM, Grafton ST, Macrae CN. Wandering minds: the default network and stimulus-independent thought. Science. 2007;315:393-5.

[68] Smallwood J, Schooler JW. The restless mind. Psychological bulletin. 2006;132:946.

[69] Raichle ME. Two views of brain function. Trends in cognitive sciences. 2010;14:180-90.

[70] Buckner RL, Andrews-Hanna JR, Schacter DL. The brain's default network. Annals of the New York Academy of Sciences. 2008;1124:1-38.

[71] Gusnard DA, Akbudak E, Shulman GL, Raichle ME. Medial prefrontal cortex and self-referential mental activity: relation to a default mode of brain function. Proceedings of the National Academy of Sciences. 2001;98:4259-64.

[72] Hasenkamp W, Wilson-Mendenhall CD, Duncan E, Barsalou LW. Mind wandering and attention during focused meditation: a fine-grained temporal analysis of fluctuating cognitive states. Neuroimage. 2012;59:750-60. 
[73] Ossandon T, Jerbi K, Vidal JR, Bayle DJ, Henaff M-A, Jung J, et al. Transient suppression of broadband gamma power in the default-mode network is correlated with task complexity and subject performance. The Journal of Neuroscience. 2011;31:14521-30.

[74] Schooler JW, Smallwood J, Christoff K, Handy TC, Reichle ED, Sayette MA. Meta-awareness, perceptual decoupling and the wandering mind. Trends in cognitive sciences. 2011;15:319-26.

[75] Jäncke L, Shah NJ. 'Hearing' syllables by 'seeing' visual stimuli. European Journal of Neuroscience. 2004;19:2603-8.

[76] Alexander JD, Nygaard LC. Reading voices and hearing text: talker-specific auditory imagery in reading. Journal of Experimental Psychology: Human Perception and Performance. 2008;34:446.

[77] Kurby CA, Magliano JP, Rapp DN. Those voices in your head: Activation of auditory images during reading. Cognition. 2009;112:457-61.

[78] Filik R, Barber E. Inner Speech during Silent Reading Reflects the Reader's Regional Accent. PloS one. 2011;6:e25782.

[79] Juphard A, Vidal JR, Perrone-Bertolotti M, Minotti L, Kahane P, Lachaux J-P, et al. Direct evidence for two different neural mechanisms for reading familiar and unfamiliar words: an intra-cerebral EEG study. Frontiers in human neuroscience. 2011;5.

[80] Yao B, Belin P, Scheepers C. Silent reading of direct versus indirect speech activates voice-selective areas in the auditory cortex. Journal of Cognitive Neuroscience. 2011;23:3146-52.

[81] Yao B, Belin P, Scheepers C. Brain 'talks over' boring quotes: Top-down activation of voice-selective areas while listening to monotonous direct speech quotations. Neurolmage. 2012;60:1832-42.

[82] Lœvenbruck H, Baciu M, Segebarth C, Abry C. The left inferior frontal gyrus under focus : an fMRI study of the production of deixis via syntactic extraction and prosodic focus. Journal of Neurolinguistics. 2005;18: 237-58.

[83] Belin P, Zatorre RJ, Lafaille P, Ahad P, Pike B. Voice-selective areas in human auditory cortex. Nature. 2000;403:309-12.

[84] Barsalou LW. Perceptual symbol systems. Behavioral and brain sciences. 1999;22:577-660.

[85] Zwaan RA. The immersed experiencer: Toward an embodied theory of language comprehension. Psychology of learning and motivation. 2003;44:35-62.

[86] Nobre AC, Allison T, McCarthy G. Modulation of human extrastriate visual processing by selective attention to colours and words. Brain. 1998;121:1357-68.

[87] Lachaux J-P, Axmacher N, Mormann F, Halgren E, Crone NE. High-frequency neural activity and human cognition: Past, present and possible future of intracranial EEG research. Progress in neurobiology. 2012.

[88] Lachaux J-P, Jerbi K, Bertrand O, Minotti L, Hoffmann D, Schoendorff B, et al. A blueprint for realtime functional mapping via human intracranial recordings. PLoS One. 2007;2:e1094.

[89] Hotopf N. Slip of the pen. In: Frith U, editor. Cognitive processes in spelling, London: Academic Press London; 1980. p. 287-311.

[90] Geschwind N. Problems in the anatomical understanding of aphasias. In: Benton AL, editor. Brain and Behavior: Research in Clinical Neuropsychology, Chicago, IL: University of Chicago Press; 1969. p. 107-28.

[91] Frith U. Reading by eye and writing by ear. In: Kolers PA, Wrolstad M, Bouma H, editors. Processing of visible language, New York: Plenum Press; 1979. p. 379-90.

[92] Luria AR. Higher cortical functions in man. New York: Basic Books; 1966.

[93] Puranik CS, Lonigan. Early writing deficits in preschoolers with oral language difficulties. Journal of learning disabilities. 2012;45:179-90.

[94] Rapp B, Benzing L, Caramazza A. The autonomy of lexical orthography. Cognitive neuropsychology. 1997;14:71-104.

[95] Cossu G. The role of output speech in literacy acquisition: Evidence from congenital anarthria. Reading and Writing. 2003;16:99-122. 
[96] Bellugi U, Klima ES, Siple P. Remembering in signs. Cognition. 1975;3:93-125.

[97] Wilson M, Emmorey K. A "word length effect" for sign language: Further evidence for the role of language in structuring working memory. Memory \& Cognition. 1998;26:584-90.

[98] McGuire P, Robertson D, Thacker A, David AS, Kitson N, Frackowiak RS, et al. Neural correlates of thinking in sign language. . Neuroreport. 1997; 8:695-8.

[99] Atkinson JR. The perceptual characteristics of voice-hallucinations in deaf people: insights into the nature of subvocal thought and sensory feedback loops. Schizophrenia bulletin. 2006;32:701-8.

[100] Baddeley A, Gathercole S, Papagno C. The phonological loop as a language learning device. Psychological review. 1998;105:158.

[101] Baddeley A. Workking memory New York: Oxford university press 1986.

[102] Luria AR. The directive function of speech in development and dissolution. Word. 1959;15.

[103] Clark A, Karmiloff-Smith A. The cognizer's innards: a psychological and philosophical perspective on the development of thought. Mind \& Language. 1993;8:487-519.

[104] Clark A. Being there: Putting brain, body, and world together again. Cambridge, MA: MIT press; 1997.

[105] Baddeley A, Chincotta D, Adlam A. Working memory and the control of action: evidence from task switching. Journal of Experimental Psychology: General. 2001;130:641.

[106] Miyake A, Shah P. Models of working memory: Mechanisms of active maintenance and executive control: Cambridge University Press; 1999.

[107] Emerson MJ, Miyake A. The role of inner speech in task switching: A dual-task investigation. Journal of Memory and Language. 2003;48:148-68.

[108] Hermer-Vazquez L, Spelke ES, Katsnelson AS. Sources of flexibility in human cognition: Dual-task studies of space and language. Cognitive psychology. 1999;39:3-36.

[109] Dunbar K, Sussman D. Toward a Cognitive Account of Frontal Lobe Function: Simulating Frontal Lobe Deficits in Normal Subjectsa. Annals of the New York Academy of Sciences. 1995;769:289-304.

[110] Lupyan G. Extracommunicative functions of language: Verbal interference causes selective categorization impairments. Psychonomic bulletin \& review. 2009;16:711-8.

[111] Gilbert AL, Regier T, Kay P, Ivry RB. Whorf hypothesis is supported in the right visual field but not the left. Proceedings of the National Academy of Sciences of the United States of America. 2006;103:489-94.

[112] Roberson D, Davidoff J. The categorical perception of colors and facial expressions: The effect of verbal interference. Memory \& Cognition. 2000;28:977-86.

[113] Cohen R, Kelter S, Woll G. Analytical competence and language impairment in aphasia. Brain and Language. 1980;10:331-47.

[114] Davidoff J, Roberson D. Preserved thematic and impaired taxonomic categorisation: A case study. Language and Cognitive processes 2004;19:137-74.

[115] Hjelmquist EK. Concept formation in non-verbal categorization tasks in brain-damaged patients with and without aphasia. Scandinavian journal of psychology. 1989;30:243-54.

[116] Kertesz A, McCabe P. Intelligence and aphasia: performance of aphasics on Raven's coloured progressive matrices (RCPM). Brain and Language. 1975;2:387-95.

[117] Hamsher K. Intelligence and aphasia. San Diego: Academic Press; 1981.

[118] Baldo JV, Dronkers NF, Wilkins D, Ludy C, Raskin P, Kim J. Is problem solving dependent on language? Brain and Language. 2005;92:240-50.

[119] Raymond JE, Shapiro KL, Arnell KM. Temporary suppression of visual processing in an RSVP task: An attentional blink? Journal of Experimental Psychology: Human Perception and Performance. 1992;18:849.

[120] Olivers CNL, Nieuwenhuis S. The beneficial effects of additional task load, positive affect, and instruction on the attentional blink. Journal of Experimental Psychology: Human Perception and Performance. 2006;32:364. 
[121] Baars BJ. Spontaneous repetitive thoughts can be adaptive: Postscript on "mind wandering". Psychological bulletin. 2010;136:208.

[122] Davis RN, Nolen-Hoeksema S. Cognitive inflexibility among ruminators and nonruminators. Cognitive Therapy and Research. 2000;24:699-711.

[123] Brewin CR, Smart L. Working memory capacity and suppression of intrusive thoughts. Journal of Behavior Therapy and Experimental Psychiatry. 2005;36:61-8.

[124] Kane MJ, Brown LH, McVay JC, Silvia PJ, Myin-Germeys I, Kwapil TR. For Whom the Mind Wanders, and When An Experience-Sampling Study of Working Memory and Executive Control in Daily Life. Psychological science. 2007;18:614-21.

[125] Rosen VM, Engle RW. Working memory capacity and suppression. Journal of memory and language. 1998;39:418-36.

[126] Geraerts E, Merckelbach H, Jelicic M, Habets P. Suppression of intrusive thoughts and working memory capacity in repressive coping. The American journal of psychology. 2007:205-18.

[127] Hofmann W, Schmeichel BJ, Baddeley AD. Executive functions and self-regulation. Trends in cognitive sciences. 2012;16:174-80.

[128] Burgess PW, Dumontheil I, Gilbert SJ. The gateway hypothesis of rostral prefrontal cortex (area 10) function. Trends in cognitive sciences. 2007;11:290-8.

[129] Munakata Y, Herd SA, Chatham CH, Depue BE, Banich MT, O'Reilly RC. A unified framework for inhibitory control. Trends in cognitive sciences. 2011;15:453-9.

[130] Frith CD. The cognitive neuropsychology of schizophrenia: Psychology Press; 1992.

[131] Jones SR, Fernyhough C. Neural correlates of inner speech and auditory verbal hallucinations: A critical review and theoretical integration. Clinical psychology review. 2007;27:140-54.

[132] Vosgerau G, Newen A. Thoughts, motor actions, and the self. Mind \& Language. 2007;22:22-43.

[133] Houde JF, Nagarajan SS. Speech production as state feedback control. Frontiers in human neuroscience. 2011;5.

[134] Wolpert DM. Computational approaches to motor control. Trends in cognitive sciences. 1997;1:209-16.

[135] Imamizu H, Kawato M. Brain mechanisms for predictive control by switching internal models: implications for higher-order cognitive functions. Psychological Research. 2009;73:527-44.

[136] Sperry RW. Neural basis of the spontaneous optokinetic response produced by visual inversion. Journal of comparative and physiological psychology. 1950;43:482.

[137] Pickering $M$, Garrod S. An integrated theory of language production and comprehension. Behavioral and Brain Science. 2013:1-64.

[138] Guenther FH, Ghosh SS, Tourville JA. Neural modeling and imaging of the cortical interactions underlying syllable production. Brain and language. 2006;96:280-301.

[139] Ford JM, Mathalon DH. Electrophysiological evidence of corollary discharge dysfunction in schizophrenia during talking and thinking. Journal of psychiatric research. 2004;38:37-46.

[140] Frith C. Neuropsychology of schizophrenia: What are the implications of intellectual and experimental abnormalities for the neurobiology of schizophrenia? British medical bulletin. 1996;52:618-26.

[141] Tian X, Poeppel D. The effect of imagination on stimulation: The functional specificity of efference copies in speech processing. Journal of cognitive neuroscience. 2013;25:1020-36.

[142] Blakemore S-J, Frith CD, Wolpert DM. Spatio-temporal prediction modulates the perception of self-produced stimuli. Journal of Cognitive Neuroscience. 1999;11:551-9.

[143] Paus TÅ, Perry DW, Zatorre RJ, Worsley KJ, Evans AC. Modulation of Cerebral Blood Flow in the Human Auditory Cortex During Speech: Role of Motor-to-sensory Discharges. European Journal of Neuroscience. 1996;8:2236-46.

[144] Shergill SS, Brammer MJ, Fukuda R, Bullmore E, Amaro E, Murray RM, et al. Modulation of activity in temporal cortex during generation of inner speech. Human Brain Mapping. 2002;16:219-27. 
Perrone-Bertolotti, M., Rapin L., Lachaux J.-P., Baciu M. \& Lœvenbruck H. (2014). What is that little voice inside my head? Inner speech phenomenology, its role in cognitive performance and its relation to self-monitoring. Behavioural Brain Research, 261, 220-239. doi: 10.1016/j.bbr.2013.12.034.

[145] Frith C. Explaining delusions of control: The comparator model 20 years on. Consciousness and cognition. 2012;21:52-4.

[146] Rapin L, Dohen M, Polosan M, Perrier P, Lœvenbruck H. An EMG study of the lip muscles during covert auditory verbal hallucinations in schizophrenia. . Journal of Speech, Language, and Hearing Research. in press.

[147] Jacobson E. Electrical measurements of neuromuscular states during mental activities. V. Variation of specific muscles contracting during imagination. American Journal of Physiology. 1931.

[148] McGuigan FJ, Dollins AB. Patterns of covert speech behavior and phonetic coding. The Pavlovian journal of biological science. 1989;24:19-26.

[149] Livesay J, Liebke A, Samaras M, Stanley A. Covert speech behavior during a silent language recitation task. Perceptual and motor skills. 1996;83:1355-62.

[150] Shimizu A, Inoue T. Dreamed speech and speech muscle activity. Psychophysiology. 1986;23:2104.

[151] Max LW. Experimental study of the motor theory of consciousness. IV. Action-current responses in the deaf during awakening, kinaesthetic imagery and abstract thinking. Journal of Comparative Psychology. 1937;24:301-44.

[152] Vanderwolf $\mathrm{CH}$. Brain, Behavior, and Mind: What do we know and What can we Know? Neuroscience \& Biobehavioral Reviews. 1998;22:125-42.

[153] Paillard J. Electrophysiologic analysis and comparison in man of Hoffmann's reflex and myotatic reflex]. Pflügers Archiv: European journal of physiology. 1955;260:448.

[154] Bensoussan L, Duclos Y, Rossi-Durand C. Modulation of human motoneuron activity by a mental arithmetic task. Human movement science. 2012.

[155] Wildgruber D, Ackermann H, Klose U, Kardatzki B, Grodd W. Functional lateralization of speech production at primary motor cortex: a fMRI study. Neuroreport. 1996;7:2791-6.

[156] Fadiga L, Craighero L, Buccino G, Rizzolatti G. Speech listening specifically modulates the excitability of tongue muscles: a TMS study. European Journal of Neuroscience. 2002;15:399-402.

[157] Pascual-Leone A, Gates JR, Dhuna A. Induction of speech arrest and counting errors with rapidrate transcranial magnetic stimulation. Neurology. 1991;41:697-702.

[158] Stewart L, Walsh V, Frith U, Rothwell JC. TMS produces two dissociable types of speech disruption. Neuroimage. 2001;13:472-8.

[159] Aziz-Zadeh L, Cattaneo L, Rochat M, Rizzolatti G. Covert speech arrest induced by rTMS over both motor and nonmotor left hemisphere frontal sites. Journal of cognitive neuroscience. 2005;17:928-38. [160] Fadiga L, Buccino G, Craighero L, Fogassi L, Gallese V, Pavesi G. Corticospinal excitability is specifically modulated by motor imagery: a magnetic stimulation study. Neuropsychologia. 1998;37:147-58.

[161] Jeannerod M. Neural simulation of action: a unifying mechanism for motor cognition. Neuroimage. 2001;14:S103-S9.

[162] Shibasaki H. Cortical activities associated with voluntary movements and involuntary movements. Clinical neurophysiology. 2012;123:229-43.

[163] Schwartz J, Basirat A, Ménard L, Sato M. The Perception-for-Action-Control Theory (PACT): A perceptuo-motor theory of speech perception. Journal of Neurolinguistics. 2012 25:336-54.

[164] Liberman A, Mattingly I. The motor theory of speech perception revised. Cognition. 198521.

[165] Nayani TH, David AS. The auditory hallucination: a phenomenological survey. Psychological medicine. 1996;26:177-90.

[166] Gould LN. Verbal hallucinations and activity of vocal musculature; an electromyographic study. The American Journal of Psychiatry. 1948.

[167] McGuigan FJ. Covert oral behavior and auditory hallucinations. Psychophysiology. 1966;3:73-80. [168] Inouye T, Shimizu A. The electromyographic study of verbal hallucination. The Journal of nervous and mental disease. 1970;151:415-22. 
[169] Stephane M, Barton S, Boutros NN. Auditory verbal hallucinations and dysfunction of the neural substrates of speech. Schizophrenia research. 2001;50:61-78.

[170] Junginger J, Rauscher FP. Vocal activity in verbal hallucinations. Journal of psychiatric research. 1987;21:101-9.

[171] Allen P, Aleman A, McGuire PK. Inner speech models of auditory verbal hallucinations: evidence from behavioural and neuroimaging studies. International Review of Psychiatry. 2007;19:407-15.

[172] Allen P, Laroi F, McGuire PK, Aleman A. The hallucinating brain: a review of structural and functional neuroimaging studies of hallucinations. Neuroscience \& Biobehavioral Reviews. 2008;32:175-91.

[173] David AS. The cognitive neuropsychiatry of auditory verbal hallucinations: an overview. Cognitive Neuropsychiatry. 2004;9:107-23.

[174] Farrer C, Franck N. Self-monitoring in Schizophrenia. . Current Psychiatry Reviews. 2007;3 24351.

[175] Seal M, Aleman A, McGuire P. Compelling imagery, unanticipated speech and deceptive memory: Neurocognitive models of auditory verbal hallucinations in schizophrenia. Cognitive Neuropsychiatry. 2004;9:43-72.

[176] McGuire PK, David AS, Murray RM, Frackowiak RSJ, Frith CD, Wright I, et al. Abnormal monitoring of inner speech: a physiological basis for auditory hallucinations. The Lancet. 1995;346:596-600.

[177] Shergill SS, Brammer MJ, Williams SCR, Murray RM, McGuire PK. Mapping auditory hallucinations in schizophrenia using functional magnetic resonance imaging. Archives of general psychiatry. 2000;57:1033.

[178] Ford JM, Mathalon DH. Corollary discharge dysfunction in schizophrenia: can it explain auditory hallucinations? International Journal of Psychophysiology. 2005;58:179-89.

[179] Choong C, Hunter, Woodruff. Auditory hallucinations in those populations that do not suffer from schizophrenia. Current psychiatry reports. 2007;9:206-12.

[180] Johns LC, van Os J. The continuity of psychotic experiences in the general population. Clinical psychology review. 2001;21:1125-41.

[181] Sommer IEC, Diederen KMJ, Blom J-D, Willems A, Kushan L, Slotema K, et al. Auditory verbal hallucinations predominantly activate the right inferior frontal area. Brain. 2008;131:3169-77.

[182] Linden DEJ, Thornton K, Kuswanto CN, Johnston SJ, van de Ven V, Jackson MC. The brain's voices: comparing nonclinical auditory hallucinations and imagery. Cerebral Cortex. 2011;21:330-7.

[183] Lavigne K, Rapin L, Metzak P, Whitman J, Jung K, Dohen M, et al. Left-dominant temporal-frontal hypercoupling in schizophrenia patients with hallucinations during speech perception Schizophrenia Bulletin. in revision

[184] Nygård M, Eichele T, Løberg E-M, Jørgensen HA, Johnsen E, Kroken RA, et al. Patients with schizophrenia fail to up-regulate task-positive and down-regulate task-negative brain networks: an fMRI study using an ICA analysis approach. Frontiers in human neuroscience. 2012;6:1-11.

[185] Hoffman RE, McGlashan TH. Synaptic elimination, neurodevelopment, and the mechanism of hallucinated 'voices' in schizophrenia. American Journal of Psychiatry. 1997;154:1683-9.

[186] Morrison AP, Haddock G, Tarrier N. Intrusive thoughts \& auditory hallucinations: a cognitive approach. Behavioural and Cognitive psychotherapy. 1995;23:265-.

[187] Copolov DL, Seal ML, Maruff P, Ulusoy R, Wong MTH, Tochon-Danguy HJ, et al. Cortical activation associated with the experience of auditory hallucinations and perception of human speech in schizophrenia: a PET correlation study. Psychiatry Research: Neuroimaging. 2003;122:139-52.

[188] Fiszdon JM, Whelahan H, Bryson GJ, Wexler BE, Bell MD. Cognitive training of verbal memory using a dichotic listening paradigm: impact on symptoms and cognition. Acta Psychiatrica Scandinavica. 2005;112:187-93.

[189] Waters F, Badcock J, Michie P, Maybery M. Auditory hallucinations in schizophrenia: Intrusive thoughts and forgotten memories. Cognitive Neuropsychiatry. 2006;11:65-83. 
Preliminary version produced by the authors.

Perrone-Bertolotti, M., Rapin L., Lachaux J.-P., Baciu M. \& Lœvenbruck H. (2014). What is that little voice inside my head? Inner speech phenomenology, its role in cognitive performance and its relation to self-monitoring. Behavioural Brain Research, 261, 220-239. doi: 10.1016/j.bbr.2013.12.034.

[190] Petitmengin C, Lachaux J-P. Microcognitive science: bridging experiential and neuronal microdynamics. Frontiers in Human Neuroscience. 2013;7:1-6. 


\section{TABLE LEGENDS}

Table 1. Brain activation patterns observed in studies that have directly compared overt vs covert/inner

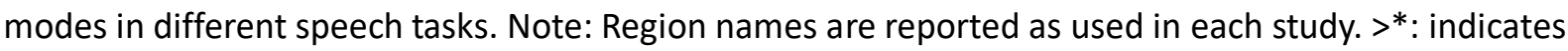
that for this region no significant activation was found for the covert condition but only in the overt condition. Abbreviation: primary motor cortex "mouth, lips, and tongue" region (MLT-PMC); primary motor cortex "inferior vocalization" region (IV-PMC); Supplementary motor area (SMA); left hemisphere (LH); right hemisphere (RH)

Table 2. Summary of current findings on inner speech and questions for future research.

\section{FIGURE LEGENDS}

Figure 1. The Predictive Model: a forward model predicts the sensory consequences of action (predicted sensory feedback). This feedback can be used to cancel out self-generated sensory events, thus distinguishing them from sensory events with an external cause. Adapted from Frith et al. (2000). 
Preliminary version produced by the authors.

Perrone-Bertolotti, M., Rapin L., Lachaux J.-P., Baciu M. \& Lœvenbruck H. (2014). What is that little voice inside my head? Inner speech phenomenology, its role in cognitive performance and its relation to self-monitoring. Behavioural Brain Research, 261, 220-239. doi: 10.1016/j.bbr.2013.12.034.

Table 1

\begin{tabular}{|c|c|c|c|c|c|c|c|c|c|}
\hline Authors & Year & Method & Task & $\begin{array}{l}\text { Modality } \\
\text { of input }\end{array}$ & Regions & BA & Hemisphere & Overt & Covert \\
\hline & & & reading & V & $\begin{array}{l}\text { inferior frontal gyrus } \\
\text { superior temporal gyrus } \\
\text { supramarginal gyrus }\end{array}$ & $\begin{array}{l}47 \\
22\end{array}$ & $\begin{array}{c}\mathrm{LH} \\
\mathrm{LH} / \mathrm{RH} \\
\mathrm{LH}\end{array}$ & & $\begin{array}{l}< \\
> \\
>\end{array}$ \\
\hline $\begin{array}{l}\text { Bookheimer } \\
\text { et al. }\end{array}$ & 1995 & TEP & naming & V & $\begin{array}{l}\text { lateral cerebellum } \\
\text { medial cerebellum } \\
\text { SMA } \\
\text { medial/inferior frontal } \\
\text { gyrus/insula } \\
\text { superior temporal gyrus }\end{array}$ & & $\begin{array}{l}\mathrm{RH} / \mathrm{LH} \\
\mathrm{RH} / \mathrm{LH} \\
\mathrm{LH} \\
\mathrm{LH} \\
\mathrm{LH}\end{array}$ & & $\begin{array}{l}> \\
> \\
> \\
> \\
>\end{array}$ \\
\hline Rosen et al. & 2000 & fMRI & $\begin{array}{l}\text { word stem } \\
\text { completion }\end{array}$ & V & $\begin{array}{l}\text { medial frontal gyrus } \\
\text { motor cortex } \\
\text { motor cortex } \\
\text { superior temporal gyrus } \\
\text { dorsolateral frontal cortex } \\
\text { frontal operculum } \\
\text { superior parietal cortex } \\
\text { Thalamus } \\
\text { Putamen }\end{array}$ & $\begin{array}{c}6 \\
4 \\
4 \\
42 \\
44 / 6 \\
\\
7\end{array}$ & $\begin{array}{c}\mathrm{LH} \\
\mathrm{LH} \\
\mathrm{RH} \\
\mathrm{LH} / \mathrm{RH} \\
\mathrm{LH} / \mathrm{RH} \\
\mathrm{LH} / \mathrm{RH} \\
\mathrm{LH} / \mathrm{RH} \\
\mathrm{LH} / \mathrm{RH} \\
\mathrm{LH} / \mathrm{RH}\end{array}$ & & $\begin{array}{l}= \\
= \\
> \\
> \\
= \\
= \\
= \\
> \\
>\end{array}$ \\
\hline $\begin{array}{l}\text { Palmer et } \\
\text { al. }\end{array}$ & 2001 & fMRI & $\begin{array}{l}\text { word stem } \\
\text { completion }\end{array}$ & V & \begin{tabular}{|l} 
frontal \\
inferior frontal gyrus \\
inferior frontal gyrus \\
anterior cingulate gyrus \\
SMA \\
inferior parietal \\
lateral cerebellum
\end{tabular} & $\begin{array}{c}6 / 44 \\
45 \\
47\end{array}$ & $\begin{array}{l}\text { RH/LH } \\
\text { LH } \\
\text { RH } \\
\text { LH/RH } \\
\text { LH } \\
\text { LH } \\
\text { RH }\end{array}$ & & $\begin{array}{l}> \\
> \\
> \\
> \\
> \\
> \\
>\end{array}$ \\
\hline
\end{tabular}


Preliminary version produced by the authors.

Perrone-Bertolotti, M., Rapin L., Lachaux J.-P., Baciu M. \& Lœvenbruck H. (2014). What is that little voice inside my head? Inner speech phenomenology, its role in cognitive performance and its relation to self-monitoring. Behavioural Brain Research, 261, 220-239. doi: 10.1016/j.bbr.2013.12.034.

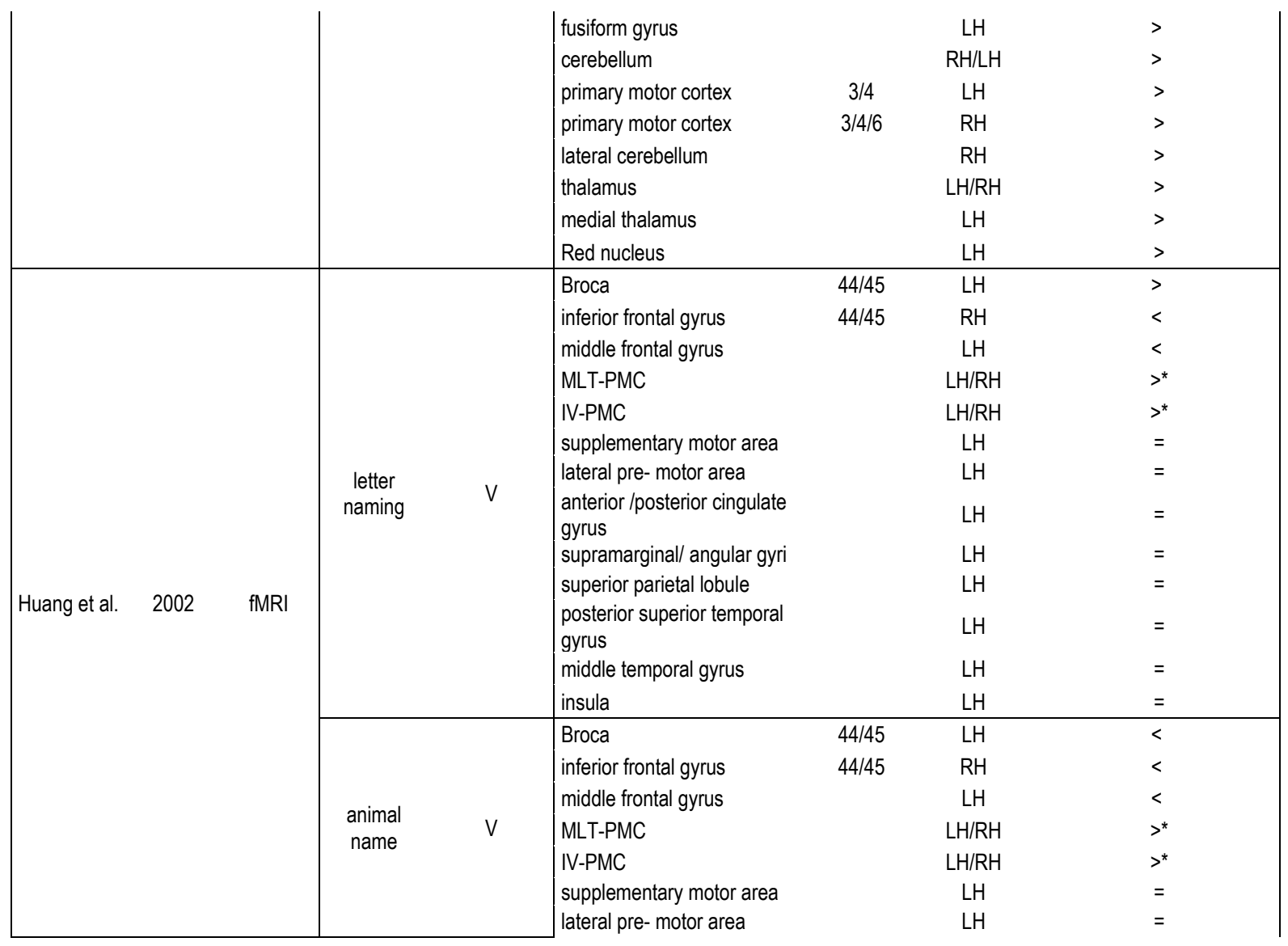


Preliminary version produced by the authors.

Perrone-Bertolotti, M., Rapin L., Lachaux J.-P., Baciu M. \& Lœvenbruck H. (2014). What is that little voice inside my head? Inner speech phenomenology, its role in cognitive performance and its relation to self-monitoring. Behavioural Brain Research, 261, 220-239. doi: 10.1016/j.bbr.2013.12.034.

\begin{tabular}{|c|c|c|c|c|c|c|c|c|}
\hline & & & & & $\begin{array}{l}\text { anterior and posterior cingulate } \\
\text { gyrus } \\
\text { supramarginal/ angular gyri } \\
\text { superior parietal lobule } \\
\text { posterior superior temporal } \\
\text { gyrus } \\
\text { middle temporal gyrus } \\
\text { insula }\end{array}$ & & $\begin{array}{l}\text { LH } \\
\text { LH } \\
\text { LH } \\
\text { LH } \\
\text { LH } \\
\text { LH }\end{array}$ & $\begin{array}{l}= \\
= \\
= \\
= \\
= \\
=\end{array}$ \\
\hline $\begin{array}{l}\text { Shuster \& } \\
\text { Lemieux }\end{array}$ & 2005 & fMRI & $\begin{array}{l}\text { word } \\
\text { repetition }\end{array}$ & A & $\begin{array}{l}\text { precentral gyrus } \\
\text { postcentral gyrus } \\
\text { precentral gyrus } \\
\text { hippocampus } \\
\text { inferior occipital gyrus } \\
\text { middle occipital gyrus } \\
\text { superior temporal sulcus } \\
\text { superior frontal gyrus } \\
\text { insula } \\
\text { cingulate } \\
\text { middle frontal gyrus } \\
\text { anterior cingulate gyrus } \\
\text { caudate nucleus } \\
\text { middle temporal gyrus } \\
\text { cerebellum (Pyramis, Uvula) } \\
\text { superior temporal gyrus } \\
\text { medial frontal gyrus } \\
\text { paracentral lobule } \\
\text { precuneus } \\
\text { postcentral gyrus } \\
\text { middle temporal gyrus } \\
\text { cerebellum }\end{array}$ & $\begin{array}{l}4 \\
3 \\
6\end{array}$ & $\begin{array}{l}\text { LH } \\
\text { LH } \\
\text { LH } \\
\text { LH } \\
\text { LH } \\
\text { LH } \\
\text { LH } \\
\text { LH } \\
\text { LH } \\
\text { LH } \\
\text { RH } \\
\text { RH } \\
\text { RH } \\
\text { RH } \\
\text { RH } \\
\text { RH } \\
\text { LH } \\
\text { LH } \\
\text { RH } \\
\text { RH } \\
\text { RH } \\
\text { RH }\end{array}$ & $\begin{array}{l}> \\
> \\
> \\
> \\
> \\
> \\
> \\
> \\
> \\
> \\
> \\
> \\
> \\
> \\
> \\
> \\
< \\
< \\
< \\
< \\
< \\
< \\
<\end{array}$ \\
\hline
\end{tabular}


Preliminary version produced by the authors.

Perrone-Bertolotti, M., Rapin L., Lachaux J.-P., Baciu M. \& Lœvenbruck H. (2014). What is that little voice inside my head? Inner speech phenomenology, its role in cognitive performance and its relation to self-monitoring. Behavioural Brain Research, 261, 220-239. doi: 10.1016/j.bbr.2013.12.034.

\begin{tabular}{|c|c|c|c|c|c|c|c|c|}
\hline \multirow{3}{*}{ Frings et al. } & \multirow{3}{*}{2006} & \multirow{3}{*}{ fMRI } & \multirow{2}{*}{\begin{tabular}{|c|c}
$\begin{array}{c}\text { verb } \\
\text { generation }\end{array}$ \\
$\begin{array}{c}\text { verb } \\
\text { reading }\end{array}$ \\
\end{tabular}} & \multirow{2}{*}{$\frac{\mathrm{V}}{\mathrm{V}}$} & \multicolumn{2}{|l|}{ paravermal lobule VI } & \multirow{2}{*}{$\begin{array}{l}\mathrm{LH} / \mathrm{RH} \\
\mathrm{LH} / \mathrm{RH}\end{array}$} & \multirow{2}{*}{$\begin{array}{l}> \\
>\end{array}$} \\
\hline & & & & & paravermal lobule VI & & & \\
\hline & & & $\begin{array}{l}\text { noun } \\
\text { reading }\end{array}$ & V & paravermal lobule VI & & $\mathrm{LH} / \mathrm{RH}$ & $>$ \\
\hline \multirow{12}{*}{ Basho et al. } & \multirow{12}{*}{2007} & \multirow{12}{*}{ fMRI } & \multirow{12}{*}{$\begin{array}{l}\text { verbal } \\
\text { semantic } \\
\text { fluency } \\
\text { (category- } \\
\text { driven } \\
\text { word } \\
\text { generation) }\end{array}$} & \multirow{12}{*}{$A$} & inferior frontal gyrus & $44 / 45$ & $\mathrm{LH}$ & $=$ \\
\hline & & & & & cingulate gyrus & 32 & LH & $=$ \\
\hline & & & & & middle frontal & 6 & LH & $=$ \\
\hline & & & & & Basal ganglia & & & $=$ \\
\hline & & & & & Thalamus & & LH & $=$ \\
\hline & & & & & superior parietal cortex & 7 & $\mathrm{RH}$ & $<$ \\
\hline & & & & & middle temporal gyrus & 21 & LH & $<$ \\
\hline & & & & & superior frontal gyrus & 6 & LH & $<$ \\
\hline & & & & & cingulate gyrus & 32 & $\mathrm{RH}$ & $<$ \\
\hline & & & & & superior frontal gyrus & 11 & $\mathrm{RH}$ & $<$ \\
\hline & & & & & inferior parietal lobe & 40 & $\mathrm{RH}$ & $<$ \\
\hline & & & & & parahippocampal gyrus & $35 / 36$ & LH & $<$ \\
\hline \multirow{10}{*}{ Forn et al. } & \multirow{10}{*}{2008} & \multirow{10}{*}{$f M R I$} & \multirow{10}{*}{$\begin{array}{c}\text { paced } \\
\text { auditory } \\
\text { serial } \\
\text { addition } \\
\text { test } \\
\text { (PASAT) }\end{array}$} & \multirow{10}{*}{ A } & superior frontal gyrus & 6 & $\mathrm{LH}$ & $>$ \\
\hline & & & & & inferior frontal gyrus & $44 / 46$ & $\mathrm{LH}$ & $>$ \\
\hline & & & & & parahippocampal gyrus & 27 & LH & $>$ \\
\hline & & & & & middle occipital gyrus/ cuneus & 18 & $\mathrm{RH}$ & $>$ \\
\hline & & & & & occipital lobe/cuneus & $4 / 17$ & LH & $>$ \\
\hline & & & & & occipital lobe/lingual gyrus & 18 & LH & $>$ \\
\hline & & & & & cerebellum & & $\mathrm{LH} / \mathrm{RH}$ & $>$ \\
\hline & & & & & fusiform gyrus & 19 & $\mathrm{RH}$ & $>$ \\
\hline & & & & & substantia nigra & & $\mathrm{RH}$ & $>$ \\
\hline & & & & & caudate body & & $\mathrm{RH} / \mathrm{LH}$ & $>$ \\
\hline \multirow{2}{*}{ Kielar et al. } & \multirow[b]{2}{*}{2011} & & & & middle frontal gyrus & 6 & $\mathrm{RH}$ & $<$ \\
\hline & & fMRI & production & V & superior frontal gyrus & 8 & $\mathrm{RH}$ & $<$ \\
\hline & & & & & postcentral gyrus & 2 & $\mathrm{RH}$ & $<$ \\
\hline & & & & & caudate & & $\mathrm{RH}$ & $<$ \\
\hline & & & & & precuneus & 7 & $\mathrm{RH}$ & $<$ \\
\hline & & & & & precentral gyrus & $4 / 6$ & $\mathrm{RH}$ & $>$ \\
\hline & & & & & precentral gyrus & 6 & LH & $>$ \\
\hline & & & & & insula & 13 & LH & $>$ \\
\hline & & & & & Claustrum & & $\mathrm{LH} / \mathrm{RH}$ & $>$ \\
\hline & & & & & $\begin{array}{l}\text { superior frontal/precentral } \\
\text { gyrus }\end{array}$ & 6 & $\mathrm{LH}$ & $>$ \\
\hline & & & & & middle frontal/precentral gyrus & 6 & $\mathrm{RH}$ & $>$ \\
\hline & & & & & anterior cingulate gyrus & $32 / 24$ & $\mathrm{RH}$ & $>$ \\
\hline & & & & & putamen & & $\mathrm{RH}$ & $>$ \\
\hline & & & & & thalamus & & LH & $>$ \\
\hline & & & & & primary motor cortex & 4 & LH & $>$ \\
\hline & & & & & premotor cortex & 6 & LH & $>$ \\
\hline Pei et al. & 2011 & ECoG & word & V/A & Broca & $44 / 45$ & LH & $>$ \\
\hline 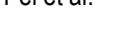 & & & repetition & & supplementary motor area & & & $>$ \\
\hline & & & & & $\begin{array}{l}\text { posterior superior temporal } \\
\text { gyrus }\end{array}$ & 22 & LH & $>$ \\
\hline & & & & & precentral gyrus & & LH & $>^{*}$ \\
\hline & & & & & inferior frontal gyrus & & $\mathrm{LH}$ & $>^{*}$ \\
\hline Moriai- & 2012 & fNIRS & naming & V & middle temporal gyrus & & $\mathrm{LH}$ & $>$ \\
\hline & & & & & middle temporal gyrus & & $\mathrm{RH}$ & $>^{*}$ \\
\hline & & & & & superior temporal gyrus & & $\mathrm{RH}$ & $>^{*}$ \\
\hline
\end{tabular}


Perrone-Bertolotti, M., Rapin L., Lachaux J.-P., Baciu M. \& Lœvenbruck H. (2014). What is that little voice inside my head? Inner speech phenomenology, its role in cognitive performance and its relation to self-monitoring. Behavioural Brain Research, 261, 220-239. doi: 10.1016/j.bbr.2013.12.034.

Table 2

\section{Current findings on inner speech}

\section{Questions for future research}

\section{Behavioural correlates}

To some researchers inner speech production is the same thing as overt speech production, except that motor execution is blocked.

To other researchers, inner speech is limited to rehearsing early stages of speech production, well ahead of articulation.

Examining speech errors during inner speech production has shown that inner speech sometimes fail to involve articulatory representations but can sometimes incorporate lower level articulatory planning.
Inner speech can be seen as truncated overt speech, but the level at which the speech production process is interrupted (abstract linguistic representation vs articulatory representation) is still debated.

Further behavioural studies on speech errors or recall could help better describing inner speech in relation to overt speech.

\section{Neural correlates}

Although inner and overt speech share a common cerebral network, they engage some cerebral regions in different ways and they produce separate activations in other cerebral regions.

Inner speech induces a more robust cerebral language lateralization than overt speech.

Some aspects of inner speech induce lesser activation in the motor and premotor cerebral regions, in the left inferior frontal gyrus, in sensory areas or in the supramarginal gyrus.

Other studies have found that inner speech recruits the left inferior frontal gyrus (pars opercularis), the left supramarginal gyrus and white matter regions adjacent to it more importantly than overt speech.
Inner speech is not just overt speech without a motor component.

It is unclear whether cerebral activity during inner speech originates from frontal (speech products) rather than temporal (speech percepts) regions? Where do auditory percepts during inner speech come from?

In order to better understand the cerebral underpinnings of inner speech in relation to overt speech generation or to speech recall, further research is needed to assess the dynamic pattern of activation and connectivity of the cerebral regions involved.

This will require, first, to monitor the fine timing of cerebral region activations, second, to assess which regions are crucial in inner speech generation and which regions interact and are synchronised.

\section{Wilful inner speech vs mind wandering}

One type of inner speech, voluntary verbal thought, is an attention-demanding task that has been associated with the task-positive (or multiple demands) network.
Comparing brain activity in tasks involving various types of inner speech might help to better account for these two modes of inner speech that seem to activate separate networks. 
Perrone-Bertolotti, M., Rapin L., Lachaux J.-P., Baciu M. \& Lœvenbruck H. (2014). What is that little voice inside my head? Inner speech phenomenology, its role in cognitive performance and its relation to self-monitoring. Behavioural Brain Research, 261, 220-239. doi: 10.1016/j.bbr.2013.12.034.

The other type of inner speech, mind wandering, involves the default mode network (DMN).

Functional connectivity studies have shown that the DMN and attention networks fluctuate in an anticorrelated and regular pattern.

\section{Inner speech and silent reading and writing}

Silent reading often involves an imagery speech component or Auditory Verbal Imagery. Inner speech is not always present during silent reading but only when our attention is involved.

Silent reading is modulated by the knowledge of the presumed author's speaking speed, the talker's voice familiarity or the reader's regional accent.

The occurrence of inner speech during silent reading has also been confirmed by neuroimaging experiments. Temporal voice areas (TVA) are activated during silent reading.

Writing engages different levels of processing such as idea generation, retrieval from semantic memory, syntactic processing, editing processes, organizing sequences of words into sentences and accessing graphemic forms.

Lesion studies show that impairments in spoken language are associated with impairments in written language production. Preschool children writing abilities studies show that children with weaker oral language skills lag behind their peers with stronger oral language skills in terms of their writing-related skills.
It is still unclear whether TVA activation during reading is early and bottom-up, or controlled by late top-down processes and therefore modulated by attention or cognitive strategies.

Further studies involving intracranial EEG may help to better understand the dynamics of inner speech during silent reading.

It is unclear whether, during writing, the transformation of abstract lexical information to graphemic forms involves inner speech or not.

Further studies may help to better understand if the orthographic lexical forms can be accessed without the mediating role of phonology and without inner speech; and also to understand if oral inner speech is a necessary condition for the acquisition of writing abilities.

\section{Inner signing}

Inner signing in deaf people recruits similar regions to inner speech. Inner processes in speech and sign may share a common cerebral substrate.

Around half of around half of all deaf people diagnosed with schizophrenia report experiencing "voices", a prevalence rate similar to auditory verbal hallucinations in hearing people with schizophrenia. Voicehallucinations in deaf people cover a broad range of phenomena, from abstract language messages to visual or kinaesthetic perceptions, such as the sense of being signed to.
Further behavioural and neuroimaging studies are necessary to better characterize inner signing and 'voice-hallucinations' in deaf people.

Questionnaires need to be better designed to avoid audiocentric biases when studying hallucinations in deaf people. 
Perrone-Bertolotti, M., Rapin L., Lachaux J.-P., Baciu M. \& Lœvenbruck H. (2014). What is that little voice inside my head? Inner speech phenomenology, its role in cognitive performance and its relation to self-monitoring. Behavioural Brain Research, 261, 220-239. doi: 10.1016/j.bbr.2013.12.034.

\section{Inner speech and cognitive performance}

Inner speech plays a role in executive control.

In task-switching, inner speech serves as a reliable internal self-cuing device that helps retrieve and activate the phonological representation of the upcoming task goal.

In problem-solving, inner speech could improve performance by improving self-regulation as well as by activating relevant lexical representations.

In more demanding situations, non-deliberate inner speech (mind wandering) seems to enhance attention. Attentional blink is reduced when observers are concurrently engaged in mind wandering.

On the other hand, it has been shown that excessive negative self-reflecting (rumination) alters cognitive performance in depressed or dysphoric patients.
It still remains to be understood why excessive negative inner speech impairs performance whereas more controlled and positive inner speech improves cognitive performance.

Comparing brain activity in tasks involving various types of inner speech and various stimulus-independent and stimulus-oriented cognitive performance might help better understanding the support or interference of inner speech with cognition. The rostral prefrontal cortex (PFC) is a good candidate for a mechanism that detects when inner speech (mind wandering) needs to be turned down to shift the attention back to the environment.

A better understanding of the cerebral network and brain dynamics engaged in healthy inner speech has potential implications for remediation therapy in patients with inner speech disorders. Patients with anxiety disorders or depression, suffering from mental rumination, could train to reduce their excessive negative inner speech, using neuro-bio-feedback training, together with orofacial relaxation techniques.

\section{Inner speech and agency}

Inner speech can be seen as a kind of action.

The predictive model of inner speech allows distinguishing self-generated speech and externally generated speech by means of an efference copy. If the actual sensory feedback matches the predicted outcome then self-authorship is experienced.

Some electromyography (EMG) and neuroimaging studies are coherent with the view that "inner speech is a kind of action", involving motor commands.

An alternative interpretation, in lines with mirror system or interaction theories of speech production/perception. The motor activity observed during inner speech could simply be an epiphenomenon of a sensory (auditory) processing of the inner voice.

A deficit in inner speech monitoring would cause verbal thoughts to be perceived as external voices, leading to
The application of the predictive model to inner speech is problematic. What are the actual sensory consequences of inner speech? Inner speech generates neither kinematics nor auditory sensations, since it is internally generated. The comparison between the predicted state and the actual state is irrelevant in the case of inner speech. If the actual sensory feedback in inner speech is proprioceptive then further studies should explain how a comparison can take place between a rich predicted somatosensory feedback and a poor actual proprioceptive feedback.

How do we produce inner speech with someone else's voice? Do we have a predictive model for each of the voices we know?

More behavioural and neuroimaging studies, providing detailed connectivity, coherence and timing information, are needed to disentangle between the predictive modelling account and alternative accounts. 
Perrone-Bertolotti, M., Rapin L., Lachaux J.-P., Baciu M. \& Lœvenbruck H. (2014). What is that little voice inside my head? Inner speech phenomenology, its role in cognitive performance and its relation to self-monitoring. Behavioural Brain Research, 261, 220-239. doi: 10.1016/j.bbr.2013.12.034.

auditory verbal hallucinations (AVH). Other accounts of $\mathrm{AVH}$ have been proposed, involving auditory memory.

Common to most of the neuroimaging studies of $\mathrm{AVH}$, inner speech and inner reading is the finding that functional connections and modulations between frontal and temporal regions seem to be at play when we monitor our own inner speech or inner reading.
A better understanding of the cerebral network and brain dynamics engaged in healthy inner speech has potential implications for remediation therapy in patients with inner speech monitoring deficits, such as schizophrenia patients. 
Preliminary version produced by the authors.

Perrone-Bertolotti, M., Rapin L., Lachaux J.-P., Baciu M. \& Lœvenbruck H. (2014). What is that little voice inside my head? Inner speech phenomenology, its role in cognitive performance and its relation to self-monitoring. Behavioural Brain Research, 261, 220-239. doi: 10.1016/j.bbr.2013.12.034.

Figure 1

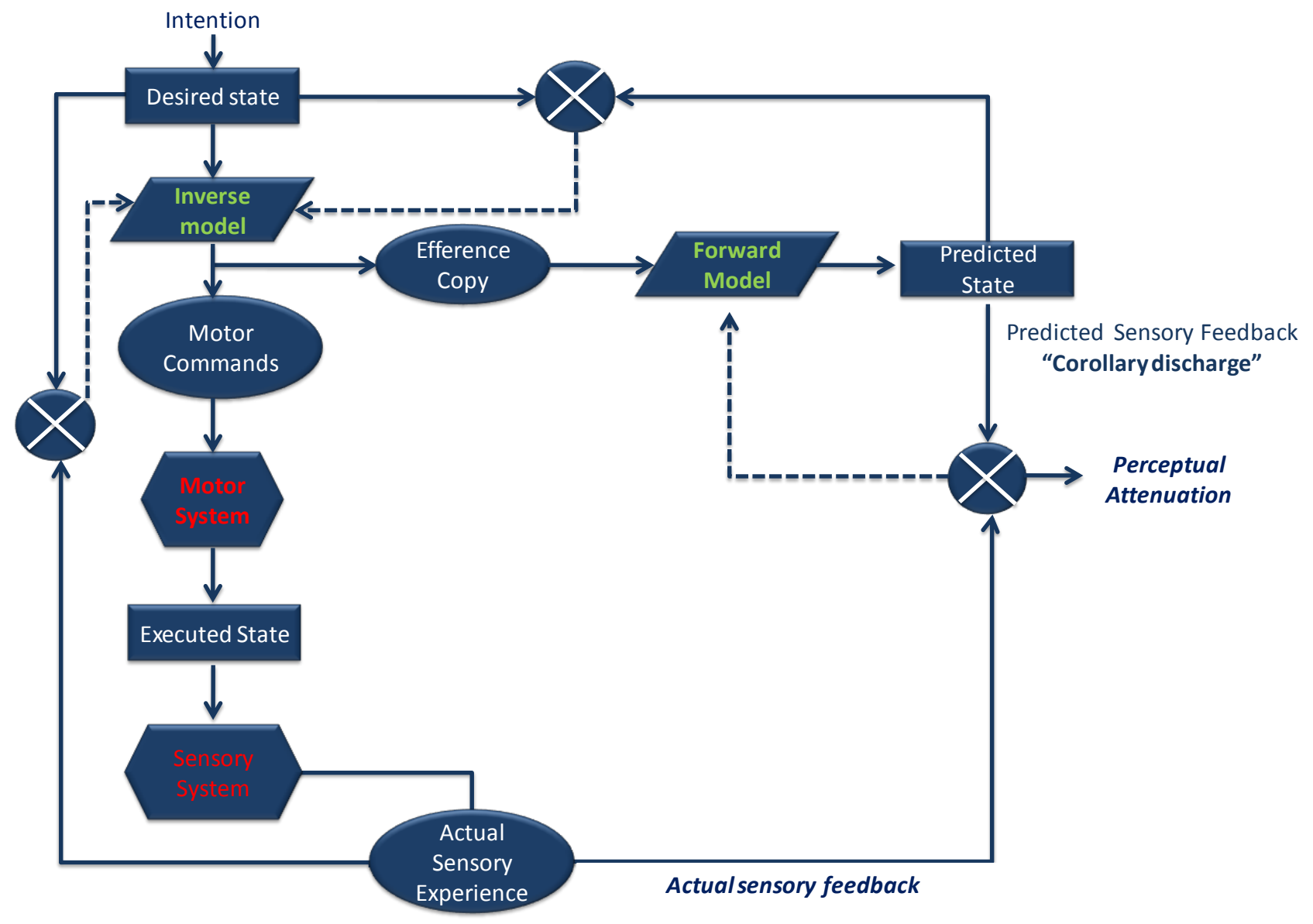

